Provided for non-commercial research and education use. Not for reproduction, distribution or commercial use.

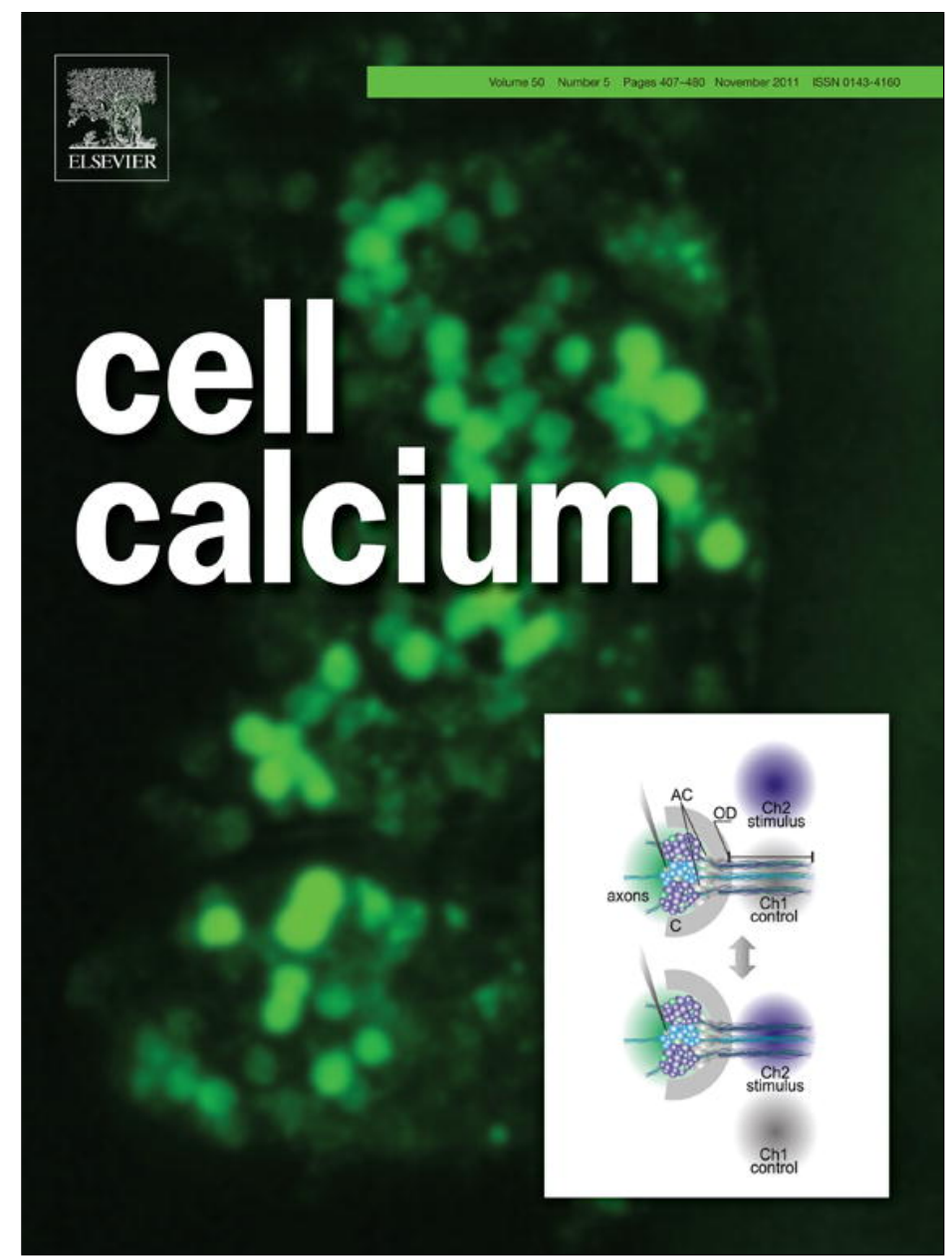

This article appeared in a journal published by Elsevier. The attached copy is furnished to the author for internal non-commercial research and education use, including for instruction at the authors institution and sharing with colleagues.

Other uses, including reproduction and distribution, or selling or licensing copies, or posting to personal, institutional or third party websites are prohibited.

In most cases authors are permitted to post their version of the article (e.g. in Word or Tex form) to their personal website or institutional repository. Authors requiring further information regarding Elsevier's archiving and manuscript policies are encouraged to visit:

http://www.elsevier.com/copyright 
Review

\title{
Redox regulation of calcium ion channels: Chemical and physiological aspects
}

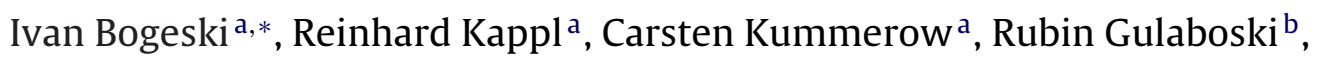 \\ Markus Hoth $^{\mathrm{a}}$, Barbara A. Niemeyer ${ }^{\mathrm{a}, *}$ \\ a Department of Biophysics, Saarland University, 66421 Homburg, Germany \\ ${ }^{\mathrm{b}}$ Department of Chemistry, Faculty of Agriculture, University Goce Delčev, Štip, Macedonia
}

\section{A R T I C L E I N F O}

\section{Article history:}

Received 14 July 2011

Accepted 26 July 2011

Available online 17 September 2011

\section{Keywords:}

Store operated calcium entry

TRP channels

Voltage gated calcium channels

Orai

STIM

Oxidation

Redox signaling

Reactive oxygen species

NADPH oxidase

Mitochondria

ROS detection

Electron paramagnetic resonance

Electrochemistry

\begin{abstract}
A B S T R A C T
Reactive oxygen species (ROS) are increasingly recognized as second messengers in many cellular processes. While high concentrations of oxidants damage proteins, lipids and DNA, ultimately resulting in cell death, selective and reversible oxidation of key residues in proteins is a physiological mechanism that can transiently alter their activity and function. Defects in ROS producing enzymes cause disturbed immune response and disease.

Changes in the intracellular free $\mathrm{Ca}^{2+}$ concentration are key triggers for diverse cellular functions. $\mathrm{Ca}^{2+}$ homeostasis thus needs to be precisely tuned by channels, pumps, transporters and cellular buffering systems. Alterations of these key regulatory proteins by reversible or irreversible oxidation alter the physiological outcome following cell stimulation. It is therefore necessary to understand which proteins are regulated and if this regulation is relevant in a physiological- and/or pathophysiological context. Because ROS are inherently difficult to identify and to measure, we first review basic oxygen redox chemistry and methods of ROS detection with special emphasis on electron paramagnetic resonance (EPR) spectroscopy. We then focus on the present knowledge of redox regulation of $\mathrm{Ca}^{2+}$ permeable ion channels such as voltage-gated $(\mathrm{CaV}) \mathrm{Ca}^{2+}$ channels, transient receptor potential (TRP) channels and Orai channels.
\end{abstract}

(c) 2011 Elsevier Ltd. All rights reserved.

\section{Basic redox chemistry of oxygen}

Many chemical processes are linked to the exchange of electrons between two or more molecular entities. The transfer of one (or more) electron(s) is associated with oxidation (loss of electron) and reduction (gain of electron) of the components. Such reactions are also known as redox reactions. The processes of reactive oxygen species (ROS) formation and elimination are exclusively of redox nature.

Molecular oxygen is the precursor of all ROS. It contains two unpaired electrons in separate (antibonding) orbitals in its outer electron sphere and is thus, by definition, a radical. Radicals have at least one unpaired electron in their orbital system and usually show high reactivity; transition metal ions also may have unpaired electrons, but are not called radicals. Although having radical character, molecular oxygen is chemically rather inert (luckily!), because high

\footnotetext{
* Corresponding authors at: Institut für Biophysik, Gebäude 58, Universität des Saarlandes, D-66421 Homburg/Saar, Germany. Tel.: +49 6841 1626453;

fax: +496841 1626060 .

E-mail addresses: ivan.bogeski@uks.eu (I. Bogeski),

barbara.niemeyer@uks.eu (B.A. Niemeyer).
}

activation energy is needed to fully reduce $\mathrm{O}_{2}$ to water. However, single electron transfers are occurring quite readily leading to the formation of several different ROS which can be either anions or neutral molecules with quite variant reactivity. ROS with one unpaired electron are radicals, but non-radical species such as $\mathrm{H}_{2} \mathrm{O}_{2}$ are also generated and classified as ROS. The oxygen radicals generally have an unstable electronic configuration and display a high reactivity because no activation energy is required for their reaction. The most common and biologically important ROS are the superoxide radical $\left(\mathrm{O}_{2}{ }^{-} \cdot\right)$ and as neutral form, the hydroperoxyl radical $\left(\mathrm{HO}_{2} \bullet\right)$, the hydroxyl radical $\left(\mathrm{OH}^{\bullet}\right)$, as well as hydrogen peroxide $\left(\mathrm{H}_{2} \mathrm{O}_{2}\right)$ and hypochloric acid ( $\left.\mathrm{HOCl}\right)$ (see Fig. 4).

Whether or not a redox reaction, i.e. an electron transfer, can potentially occur between two compounds ( 1 and 2 ) is depending on the effective redox potentials of both redox couples Ox1/Red1 and $\mathrm{Ox} 2 / \mathrm{Red} 2$. The effective redox potential $\mathrm{E}$ of a certain redox couple is defined by the Nernst relation:

$E=E_{\mathrm{o}}+2.303 \frac{R T}{n F} \lg \frac{[\mathrm{Ox}]}{[\operatorname{Red}]}$

In the second term the factor $2.303 R T /(n F)$ includes the temperature dependence ( $T$, absolute temperature) and the 
number of electrons transferred $(n) . R$ and $F$ are the gas constant $\left(8.314 \mathrm{~J} \mathrm{~mol}^{-1} \mathrm{~K}^{-1}\right)$ and the Faraday constant $\left(96,487 \mathrm{C} \mathrm{mol}^{-1}\right)$, respectively (The coefficient arises from the base transformation going from the natural to the decadic logarithm). This factor is also termed Nernst factor and yields $59 \mathrm{mV}$ at $25^{\circ} \mathrm{C}$ or $62 \mathrm{mV}$ at physiologic $37^{\circ} \mathrm{C}$ for a single electron transferred $(n=1)$.

This second term becomes zero, when the concentrations of the oxidized and reduced form of a redox couple are equal. In that case, the effective redox potential $E$ adopts the value of the standard reduction potential $E_{0}$, which is measured in relation to the potential of the standard hydrogen electrode (at $25^{\circ} \mathrm{C}$, all effective concentrations at $1 \mathrm{~mol} / \mathrm{L}$ and/or partial pressures of $1013 \mathrm{hPa}$ for gases). The potential of the standard hydrogen electrode (SHE) is by convention defined as zero, so that the redox potential of a redox couple adopts positive or negative $E_{\mathrm{o}}$ values depending on its electron accepting or donating properties relative to the $\mathrm{H} / \mathrm{H}^{+}$redox couple. Because the SHE reference potential is defined in the presence of $1 \mathrm{~mol} / \mathrm{L}$ of $\mathrm{H}^{+}$-ions (i.e. $\mathrm{pH}=0$ ), it also explicitly depends on the prevailing $\mathrm{pH}$. For the biological relevant $\mathrm{pH}=7$ the reference potential at $25^{\circ} \mathrm{C}$ of the SHE is given as

$E_{\mathrm{o}}^{7}(\mathrm{SHE})=E_{\mathrm{o}}-2.303 \frac{R T}{F} \mathrm{pH}=-413 \mathrm{mV}$

with $E_{0}=0 \mathrm{~V}$ as mentioned above.

Consequently, the standard redox potentials of a redox couple involving $\mathrm{H}^{+}$-ions may be determined with respect to the SHE, but can be corrected for $\mathrm{pH}=7$ by adding $-413 \mathrm{mV}$. For example, the value $E_{0}$ for the reduction of oxygen to water $\left(1 / 2 \mathrm{O}_{2}+2 \mathrm{H}^{+}+2 \mathrm{e}^{-} \rightarrow \mathrm{H}_{2} \mathrm{O}\right)$ is given as $+1.23 \mathrm{~V}$ at standard conditions and translates to $E_{0}{ }^{\prime}=0.82 \mathrm{~V}$ corrected for $\mathrm{pH}=7$. For biologic and physiologic applications usually the corrected (and primed) values $E_{0}{ }^{\prime}$ of the midpoint redox potential are of relevance to predict possible redox reactions.

A redox reaction of two compounds ( 1 and 2 ) generally is written in the form

$\operatorname{Red} 1+\mathrm{Ox} 2 \leftrightarrow \mathrm{Ox} 1+\operatorname{Red} 2$,

for which the so called half-reaction (say, of compound 1) is presented as

$$
\text { Red } 1 \leftrightarrow \mathrm{Ox} 1+n \mathrm{e}^{-}+m \mathrm{H}^{+}
$$

including explicitly the transfer of $n$ electrons and possibly $m$ protons.

The effective redox potential of the pair Ox1/Red 1 is defined according to the Nernst equation by

$E=E_{0}+2.303 \frac{R T}{n F} \lg \frac{[\mathrm{Ox} 1]}{[\operatorname{Red} 1]}+2.303 m \frac{R T}{n F} \lg \left[\mathrm{H}^{+}\right]$

Transforming to the midpoint potential $E_{\mathrm{o}}{ }^{\prime}$ at $\mathrm{pH} 7$ and using the definition $\mathrm{pH}=-\lg \left[\mathrm{H}^{+}\right]$we can write referring to $\mathrm{pH} 7$ in biologic systems

$E=E_{\mathrm{o}}^{\prime}+2.303 \frac{m}{n} \frac{R T}{F}(7-\mathrm{pH})+2.303 \frac{R T}{n F} \lg \frac{[\mathrm{Ox} 1]}{[\operatorname{Red} 1]}$

Combining the constants and assuming a temperature of $37^{\circ} \mathrm{C}$ we finally obtain

$E=E_{o}^{\prime}+\frac{m}{n} 61.55 \mathrm{mV}(7-\mathrm{pH})+\frac{61.55 \mathrm{mV}}{n} \lg \frac{[\mathrm{Ox} 1]}{[\operatorname{Red} 1]}$

where the effective potential $E$ is explicitly dependent on a pH shift from a value of 7 and on the concentrations of oxidized and reduced form (with $E_{\mathrm{o}}{ }^{\prime}$ and $E$ in $\mathrm{mV}$ ). The pH-term is zero when no protons are involved, $m=0$, or when the $\mathrm{pH}$ equals 7 . It adds to the $E_{\mathrm{o}}{ }^{\prime}$ value, if the $\mathrm{pH}$ is below 7 or diminishes it for $\mathrm{pH}$ values above 7. For one $\mathrm{pH}$ unit deviation from $\mathrm{pH} 7$ and for equal numbers of protons $m$ and electrons $n$ transferred, $E_{0}{ }^{\prime}$ is increased or decreased by about $62 \mathrm{mV}$. The "concentration-term" (third term in Eq. (1) above) depends on the concentrations of Ox 1 and Red 1 and the number of electrons $n$ transferred in the redox process and is zero for equal concentrations of both components of the redox pair Ox1 and Red1.

Let us now consider an important biological half reaction, the formation of the neutral ubiquinone radical $\mathrm{UQH}^{\bullet}$ after addition of an electron and a proton to UQ

$\mathrm{UQ}+\mathrm{e}^{-}+\mathrm{H}^{+} \leftrightarrow \mathrm{UQH}^{\bullet}$

for which a midpoint potential $E_{\mathrm{o}}{ }^{\prime}=-40 \mathrm{mV}$ is found in the literature. To visualize the $\mathrm{pH}$ - and concentration dependence of this redox process one can rewrite Eq. (1) with the relation $[O x 1]+[\operatorname{Red} 1]=c^{*}$, identifying Ox1 with UQ and Red1 with $\mathrm{UQH}^{\bullet}$ and $c^{*}$ being the total concentration. Then, the effective redox potential can be plotted as a function of the relative concentration of the reduced species $c_{\operatorname{Red} 1}=[\operatorname{Red} 1] / \mathrm{c}^{*}$ ranging from 1 (no Ox1 present) to 0 (no Red1 present). For equal concentrations ( $\operatorname{Red} 1=\mathrm{Ox} 1)$ the midpoint potential for different $\mathrm{pH}$ values can be read from the corresponding curves at $c_{\text {Red } 1}=0.5$ as indicated in Fig. 1 . The $E_{0}{ }^{\prime}$-values are shifted in positive direction for decreased $\mathrm{pH}$ and towards more negative values for increased $\mathrm{pH}$ compared to the value for $\mathrm{pH}$ 7. When the portion of Red 1 drops to $10 \%$ $\left(c_{\text {Red1 }}=0.1\right)$ of the total concentration, the effective potential $E$ for $\mathrm{pH} 7.4$, for example, increases from $-65 \mathrm{mV}$ to $-5.9 \mathrm{mV}$ as can be inferred from the intersection of the vertical line at $c_{\operatorname{Red} 1}=0.1$ with the curve (Fig. 1A). If the fraction of Red 1 amounts to only $0.1 \%$ $\left(c_{\text {Red }}=10^{-3}\right)$ then $E$ increases even further to $+120 \mathrm{mV}$. This short example demonstrates that significant shifts in redox potential have to be considered for low concentrations of the reduced form Red1. It is also obvious from the graphs that $E$ is decreasing massively as soon as the portion of Red 1 increases and Ox1 decreases proportionally (vertical line at $c_{\text {Red } 1}=0.9$ in Fig. $1 \mathrm{~A}$ ). Such situations where one part of a redox couple is present only in minor concentrations are often found in biologicaly relevant redox reactions.

As an example, let us analyse a common biological reaction, the formation of the semiquinone radical from superoxide, in more detail, which can be described again by the formal redox equation

$\operatorname{Red} 1+\mathrm{Ox} 2 \leftrightarrow \mathrm{Ox} 1+\operatorname{Red} 2$

and explicitly by

$\mathrm{O}_{2}{ }^{-} \cdot \mathrm{UQ} \leftrightarrow \mathrm{O}_{2}+\mathrm{UQH}^{\bullet}$

This reaction can spontaneously proceed from the left to the right side, if the redox potential of the oxidant $\mathrm{UQ} / \mathrm{UQH}^{\bullet}$ is more positive than that of the reductant $\mathrm{O}_{2} / \mathrm{O}_{2}{ }^{-} \cdot$ (i.e. the free energy $\Delta G<0$ ). The midpoint potential $E_{\mathrm{o}}{ }^{\prime}$ of both redox pairs (for equimolar concentrations of $\mathrm{Ox} / \mathrm{Red}$ ) are given in tables as $E_{\mathrm{o}}{ }^{\prime}\left(\mathrm{UQ} / \mathrm{UQH}^{\bullet}\right)=-65 \mathrm{mV}$ and $\mathrm{E}_{\mathrm{o}}{ }^{\prime}\left(\mathrm{O}_{2} / \mathrm{O}_{2}{ }^{-}\right)=-170 \mathrm{mV}$, so that electrons can principally be transferred from superoxide to UQ to form semiquinone radicals until an equilibrium is reached. This can be visualized in Fig. 1B by an arrow parallel to the $x$-axis starting from the midpoint potential of $\mathrm{O}_{2} / \mathrm{O}_{2}{ }^{-} \cdot$ which intersects with the curve of $\mathrm{UQ} / \mathrm{UQH}^{\bullet}$ at about $\mathrm{c}_{\mathrm{Red}}=0.98$. Hence, when we have equimolar amounts of $\mathrm{O}_{2} / \mathrm{O}_{2}{ }^{-}$(and $E=-170 \mathrm{mV}$ ) then $98 \%$ of UQ will be reduced to the semiquinone radical (right arrow in Fig. 1B). Of course we can reverse the arrow, which then means that we need $98 \%$ of reduced UQ to drive the reaction such that half of the oxygen is converted to superoxide, and we need an even higher portion of $\mathrm{UQH}^{\bullet}$ to increase the concentration of the superoxide radical further.

For a more realistic situation with a much smaller relative concentration of superoxide $\left(3 \times 10^{-3}\right)$ we will have about $13 \%$ of $\mathrm{UQH}^{\bullet}$ (left arrow in Fig. 1B), or vice versa, we need at least that amount 
A

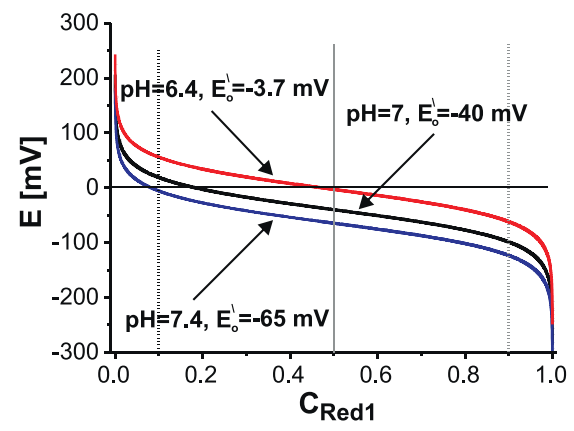

B

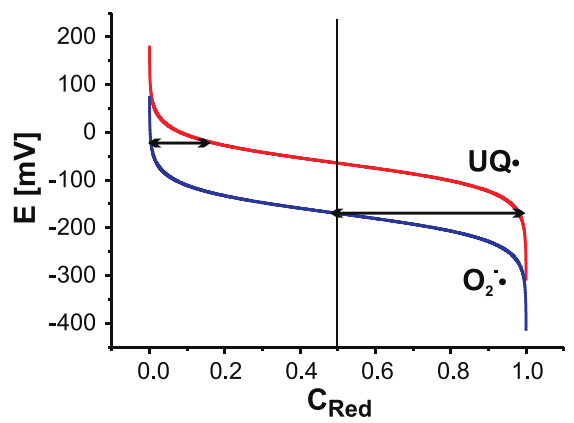

Fig. 1. Visualization of redox potential dependencies. (A) Dependence of the effective redox potential of a redox couple involving proton transfer on the portion of the normalized reduced species $\mathrm{c}_{\mathrm{Red} 1}$. (B) Redox equilibrium of the pairs $\mathrm{UQ} / \mathrm{UQH} \bullet$ and $\mathrm{O}_{2} / \mathrm{O}_{2} \cdot \bullet$. For detail see text.

of $\mathrm{UQH}^{\bullet}$ to obtain a fraction of $3 \times 10^{-3}$ of produced superoxide radical. If we have only oxidized components present (e.g. $\mathrm{O}_{2}$ and $\mathrm{UQ}$ ) in our reaction mixture no $\mathrm{e}^{-}$-transfer will happen unless the superoxide or the semiquinone are formed spontaneously by other processes. It is noted, that this discussion of redox equilibrium concurs with the chemical equilibrium model in which the equilibrium constant is defined as the ratio of reactant concentrations. In this regard, the redox potential $E$ may be viewed as a parameter that is adjustable to shift the relative concentrations of the redox couples. This perception is the basis for all voltammetric experiments, in which the potentials at electrode interfaces bias the redox conversion of reactants.

In biological processes a single electron transfer (SET) to oxygen is the first step in the formation of reactive oxygen species. Because $\mathrm{O}_{2}{ }^{-} \cdot$ is a rather unstable compound it undergoes additional reduction to $\mathrm{H}_{2} \mathrm{O}_{2}$, either spontaneously (via dismutation) or in a process catalysed by superoxide dismutases (SOD). $\mathrm{H}_{2} \mathrm{O}_{2}$, on the other hand, is much more stable than $\mathrm{O}_{2}{ }^{-} \cdot$ despite its high midpoint redox potential $E_{\mathrm{o}}{ }^{\prime} \sim 1.35 \mathrm{~V}$ due to its slow kinetics of electron transfer, and it is a weakly oxidizing agent under physiological conditions. Its neutrality and low reactivity enable $\mathrm{H}_{2} \mathrm{O}_{2}$ molecules to cross cellular membranes, and to travel certain distances and finally to interact with particular biological targets thus acting as second messengers in many cellular processes. As for many other second messengers (including $\mathrm{Ca}^{2+}$ ), high concentrations of $\mathrm{H}_{2} \mathrm{O}_{2}$ will have toxic effects leading to cellular apoptosis and necrosis [1]. A much more deleterious ROS than $\mathrm{H}_{2} \mathrm{O}_{2}$ is the hydroxyl radical $\left(\mathrm{OH}^{\bullet}\right)$, which is one of the most reactive chemical species known. It can be formed from $\mathrm{H}_{2} \mathrm{O}_{2}$ in presence of trace metals via the Fenton reaction or from $\mathrm{O}_{2}{ }^{-}$and $\mathrm{H}_{2} \mathrm{O}_{2}$ via the Haber-Weiss reaction [2]. The very high $E_{\mathrm{o}}{ }^{\prime}$ of $\mathrm{OH}^{\bullet}(2.31 \mathrm{~V})$ will enable these reactive species to react with many proteins, lipids and even DNA within a living cell, finally leading to unwanted effects. Because of its high reactivity, it will immediately oxidize the molecules in its vicinity without being able to diffuse over a noticeable distance.

The basic chemical principles outlined above are universal and apply also in biological systems. Here, the situation is of course much more complex and the identification of the major sources of ROS, their localisation and the kinetics of ROS production are of major importance for the interpretation of cellular redox signaling.

\section{Sources of ROS in biological systems}

ROS in biological systems can be generated by the NADPH oxidase family members NOX1-5 and DUOX1 and 2, mitochondrial electron transfer chain (ETC), xantine oxidases, lipoxygenases, cyclooxygenases, heme containing proteins, such as cytochrome
P450 enzymes and also by the Fenton reaction in compartments with a high concentration of ferrous iron. The most prominent cellular sources of ROS are the NADPH oxidases and the mitochondrial ETC [1].

\subsection{NADPH oxidase enzymes (NOX)}

The family of NOX enzymes consists of seven members: five conventional protein complexes NOX1-5 and two dual oxidases DUOX1 and 2 [3-6]. The first characterized NOX enzyme was the NOX2 enzyme also known as phagocyte NADPH oxidase because of its high expression in granulocytes and monocyte-derived cells which use ROS for elimination of pathogens (see Fig. 4). Afterwards, other members of the NOX family were cloned and identified in many different tissues indicating a more general role for cellular ROS production. With possibly one exception (NOX4) [7], NOX enzymes are not constitutively active. They are activated upon physiological stimuli by assembly of their core NOX subunit together with accessory subunits on the phagosome- and/or the plasma membrane. This is followed by an electron transfer from cytosolic NADPH to molecular oxygen at the contralateral side leading to subsequent formation of $\mathrm{O}_{2}{ }^{-} \cdot$, which is rapidly dismutated into the more stable $\mathrm{H}_{2} \mathrm{O}_{2}$. It is important to note that $\mathrm{Ca}^{2+}$ plays an important role for NOX function, not only for NOX5 and DUOX1 and 2 which contain EF hands and are directly activated by an increase in $\left[\mathrm{Ca}^{2+}\right]_{i}[4,8,9]$, but also for the other members of the NOX family.

\subsection{Mitochondria}

While protons are pumped to the inner mitochondrial membrane (IMM) during the process of oxidative phosphorylation and ATP production, electrons are transported along the electron transfer chain (ETC) where they ultimately reduce oxygen to $\mathrm{H}_{2} \mathrm{O}$. The proton gradient across the IMM is essential for ATP production. Because of the relatively high difference in standard reduction potentials between complex I and complex IV of around $0.7 \mathrm{~V}$, a fraction of the transferred electrons escapes and reduces molecular oxygen in their vicinity into $\mathrm{O}_{2}{ }^{-} \cdot$. Some studies report a rather high percentage of electrons (1-2\%) escaping from the ETC while other estimate a much lower fraction $(<0.1 \%)$. The reason for this discrepancy may arise from differences in experimental approaches, such as use of isolated mitochondria vs. intact cells and variable external partial pressure of oxygen $[2,10]$. Under physiological conditions the steady state concentrations of mitochondrial $\mathrm{O}_{2}{ }^{-}$which will then be dismutated by mitochondrial superoxide dismutase ( $\mathrm{mSOD}$ ) into $\mathrm{H}_{2} \mathrm{O}_{2}$ are estimated to be in low picomolar $\left(\mathrm{O}_{2}{ }^{-}\right.$) to low nanomolar range $\left(\mathrm{H}_{2} \mathrm{O}_{2}\right)$ [11]. 
Similar as for NOX enzymes, mitochondrial function is tightly controlled by $\mathrm{Ca}^{2+}$ ions $[12,13]$. An increase in the mitochondrial $\mathrm{Ca}^{2+}$ concentration leads to increased ROS production which then may affect other redox sensitive signaling pathways [12,14-17]. Further information on mitochondrial ROS production can be found in references [18-22].

\section{Detection of ROS}

As their name implies, ROS are very reactive and thus extremely unstable compounds. Hence, their detection in living cells is a challenging task. Presently, almost all techniques rely on detecting end-products of chemical reactions induced by ROS. Probably the most popular tools of ROS detection are fluorescent or luminescent dyes or proteins. The development and application of these sensors has been nicely described elsewhere [23-30]. In addition, ROS can be detected by electrochemistry and electron paramagnetic resonance (EPR) spectroscopy, physico-chemical techniques increasingly applied in biological studies but still not exploited to their full potential.

Here, we will briefly summarize the application of redox sensitive dyes, protein sensors and electrochemistry and describe in more detail EPR spectroscopy and its application in physiological studies.

\subsection{Dyes}

Fluorescent or luminescent dyes have been widely applied in biological systems for detection of ROS. Generally, they exist in an ester form such that they can be loaded in the cellular cytosol and/or organelles and indicate intracellular changes in ROS production. Some dyes, however, do not cross the plasma membrane (PM) and can be used to determine extracellular ROS concentration. A number of different dyes are available on the market, but the most popular ones are the dichlorofluorescein (DCF) based ones. Other commonly used fluorescent dyes are based on rhodamine, ethidine and the phenoxazine backbones, well known examples include Amplex Red and Amplex Ultra Red which are based on phenoxazine (resourfin). Commonly used chemiluminescent based indicators include lucigenin as a specific detector for $\mathrm{O}_{2}{ }^{-}$while luminol has mostly been used as an indicator for general ROS production.Based on redox active substituents in the benzene ring and using the nucleophilic character of some reactive species, the development of a new generation of dyes with potentially improved characteristics has been described [31-40].Because of the quite complex chemistry of all of these dyes, great care has to be taken in designing biological experiments and in their interpretation. For example, there is evidence that DCF may produce secondary radicals induced by its own oxidation [41].

Advantages: Relatively cheap, intracellular ROS measurement possible, detection by any kind of fluorescence or luminescence reader, can be used in any cell type

Disadvantages: Unspecific or partially specific, photosensitive, autooxidation, irreversible, interference with cellular redox state, leakage, no ratiometric measurements possible

\subsection{Proteins}

The invention of genetically encoded fluorescent sensors for measurements of intracellular ROS was a significant advance in the field of redox biology. Redox-sensitive, reactive cysteine containing green fluorescent proteins (roGFPs), yellow fluorescent proteins (rxYFPs) and fusions of redox sensitive oxyR with YFP (HyPer) have already been successfully used in various studies [42-47]. In addition, several Förster resonance energy transfer (FRET) based sensors have been used as redox sensitive probes [48]. Improved versions of these sensors and creation of transgenic animals will surely bring further advances in redox signaling research. For a detailed summary of the current state of the art see [30].

Advantages: Ratiometric (HyPer and roGFP), intracellular ROS measurements, organelle targeting, relatively specific, suitable for in vivo measurements, available for further genetic engineering, transgenic animals

Disadvantages: Moderate dynamic range, $\mathrm{pH}$ sensitivity, interference with cellular redox state, depends on "transfectability" of cell type if not used as a knock-in construct

\subsection{Electrochemistry}

Electrochemical techniques have been applied to detect various reactive oxygen and nitrogen species [49-54]. Some of these utilize direct detection of diverse reactive species based on their differential redox potentials, while others use electrodes modified with molecules or proteins with electrocatalytic activity towards the species of interest. Single-cell amperometric measurements are another elegant approach for parallel detection of ROS and RNS production [55-57].

Although all of the above mentioned techniques have regularly been used in answering many biological questions, the discovery of Scanning ElectroChemical Microscopy (SECM) was a revolutionary step towards the "in-vivo" detection of ROS. SECM involves the use of a mobile ultramicroelectrode probe, with which it is possible to scan the surface of a single cell in order to get closer insight into its redox activity and surface morphology. Such experiments are performed in either an amperometric or a potentiometric mode. The topographic and chemical information about the electrochemical processes taking place at a given site of a single-cell can be obtained from the faradaic currents measured at the working ultramicroelectrode directly or after additional modification using redox mediators. Main requirements for the successful accomplishment of such electrochemical measurements are accurate placement of the tip of microelectrode(s), precise determination of the tip-to-cell distance, and the appropriate selectivity of the ultramicroelectrodes for species that may change in concentration as a result of various cellular actions [58,59].

Advantages: Possibility to detect ROS at different sites on the PM, relatively specific, detection of low ROS concentrations, fast instrumental output.

Disadvantages: Easy pollution of the working electrodes, possible interferences from other redox systems, expensive set-up, need for specialist

\subsection{EPR spectroscopy}

EPR spectroscopy is based on the absorption of microwave radiation by molecules with at least one unpaired electron exposed to an external magnetic field. Therefore, EPR is the method of choice to study radicals which are selectively detected in complex chemical systems prevailing in biological or physiological experiments. Such paramagnetic molecules, in the simplest case, carry a spin $S=1 / 2$ arising from a single unpaired electron which may be imagined as little dipole magnet. Hence, in a magnetic field the two possible spin states $m_{S}= \pm 1 / 2$, sometimes called "spin up" and "spin down" states, adopt different energies and populations, so that transition between the lower and the higher energy state can be induced by electromagnetic radiation providing an energy exactly bridging this energy gap (Fig. 2A). For technical reasons this absorptive process is recorded as the first derivative of an absorption line (Fig. 2C). Typically, EPR experiments are performed at magnetic fields around $350 \mathrm{mT}$ (=milliTesla) and corresponding microwave frequencies of $\sim 9.5 \mathrm{GHz}$ (X-band). The latter is highly stabilized and continuously 
A

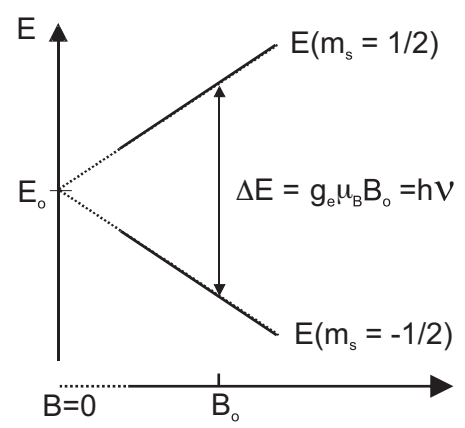

C

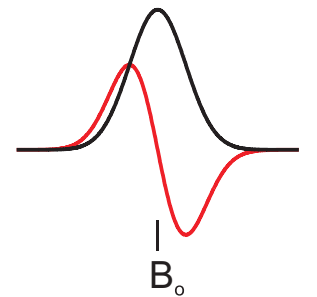

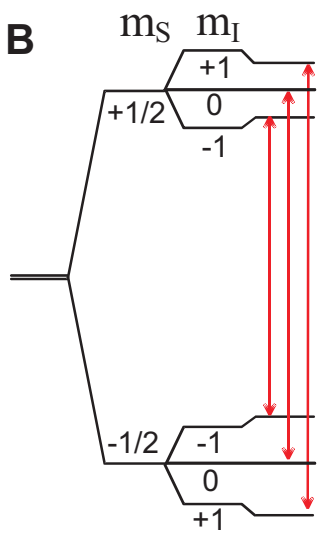

D

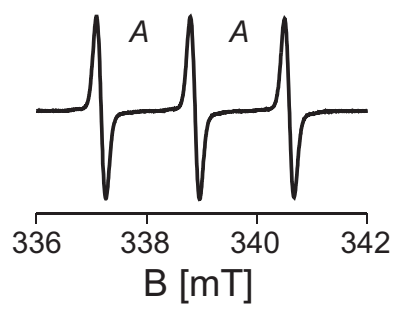

Fig. 2. Precepts of EPR. (A) The energy level separation of the two electron spin states depends on the applied magnetic field. The microwave induced transition is indicated by the arrow. (B) The electron levels are split by a ${ }^{14} \mathrm{~N}$-nucleus giving three EPR transitions. (C) The absorption spectrum at $\mathrm{B}_{\mathrm{o}}$ is recorded as first derivative. (D) The associated spectrum shows three EPR lines, $A$ is the hyperfine splitting of ${ }^{14} \mathrm{~N}$.

irradiating the sample in the measuring cavity (continuous wave, cw-mode) while the field is swept in the desired range to record the spectrum.

The unpaired electron of a molecule may additionally interact with one or more nuclei in its vicinity. If these have a nuclear spin $I \neq 0$, the unpaired electron spin "is seeing" the magnetic field caused by the nuclear spins. According to the possible nuclear spin states the induced magnetic field adds to or subtracts from the applied external field, so that several lines are appearing. For a proton with $I=1 / 2$ the two spin states with $m_{\mathrm{I}}= \pm 1 / 2$ result in four energy states for the interaction of the electron, so that two EPR lines are observed separated by the hyperfine interaction A. In many biological or physiological EPR experiments the finally observed radical spectrum is related to a nitroxide group. Here, the unpaired electron spin is located mainly in the orbitals of an NO-group and is interacting with the nuclear spin $I=1$ of the nitrogen. The three nuclear spin states of ${ }^{14} \mathrm{~N}, m_{\mathrm{I}}=+1,0,-1$, split the two electron states into a total of six energy levels which can be connected by three EPR transitions leaving the $\mathrm{m}_{\mathrm{I}}$-values unchanged ( $\Delta m_{\mathrm{I}}=0$, selection rule) (Fig. $\left.2 \mathrm{~B}\right)$. This yields the characteristic three line spectrum of nitroxide based radicals (Fig. 2D). In general, from a single nucleus with spin I in an EPR spectrum $2 I+1$ lines separated by the hyperfine constant A can be observed. When several nuclear spins are involved, the number of EPR-lines increases with the number of spin states, so that EPR spectra with many lines may be recorded. Finally, it is important that in EPR radicals can be analysed under physiological conditions at ambient temperatures or $37^{\circ} \mathrm{C}$. In aqueous solutions the recorded EPR radical spectra usually can be interpreted rather easily, because all complicating anisotropic effects of the EPR parameters are irrelevant. For measurements in solids, powders or frozen solutions a more elaborate approach to explain the EPR spectra is necessary.

In principle, the radical forms of $\mathrm{ROS}\left(\mathrm{O}_{2}{ }^{-}, \mathrm{HO}_{2} \bullet, \mathrm{OH}^{\bullet}\right)$ generated in biological systems are accessible by EPR spectroscopy due to their unpaired electron spin. However, in real conditions the very low steady state concentrations and short life times (several $\mu$ s to ns) together with unfavorable relaxation properties impede their direct observation. To circumvent these restrictions, EPR spin trapping methods have been continuously developing since the mid 1960s. Up to now, an abundant variety of traps with different structures and properties have evolved for variable purposes such as chemical, biological and medicinal studies. A survey of available trapping compounds together with their application can be found in several reviews or books $[2,60,61]$. Their principal mode of operation is to react with the short lived radicals forming a spin adduct (or transfer a single electron), and thus adopting an unpaired electron state. This new radical or spin adduct has a considerably longer lifetime (at least in the seconds or minutes range up to several hours or days) and accumulates to well accessible concentrations easily detectable by EPR.

For measuring oxygen free radicals two major groups of spin traps are generally used, the nitrone compounds and cyclic hydroxyl amines. The chemical structures of representative spin trap reagents are shown in Fig. 3A and B. Their chemical features such as solubility, stability, trapping efficiency and cell permeability can be altered and adjusted by changing or adding specific side groups.

The central property of the nitrones (Fig. $3 \mathrm{~A}$ ) is the presence of a double bond associated with the NO group. Radicals tend to attach to this electron rich region being covalently bound to the trap structure. For example, DMPO is stabilizing the $\mathrm{O}_{2}{ }^{-} \cdot$ radical at the $\mathrm{CH}$-position next to NO yielding a characteristic 12-line spectrum, caused by the interaction of ${ }^{14} \mathrm{~N}$ and several nearby protons [62]. When $\mathrm{OH}^{\bullet}$ is reacting, a four-line spectrum is observed, thus allowing to distinguish the primary reactant. However, it is also observed that the DMPO-OOH adduct is transforming to DMPO$\mathrm{OH}$ within minutes, so that a distinction of involved radicals is not always clear cut. The trap PBN shows a modified nitroxide three line EPR spectrum after reaction with carbon centered or $\mathrm{OH}^{\bullet}$ radicals (Fig. 3C). On the other hand, the cyclic hydroxyl amines (Fig. 3B), $\mathrm{CPH}$ or $\mathrm{CMH}$, are transformed to a radical state by oxidation with 
A

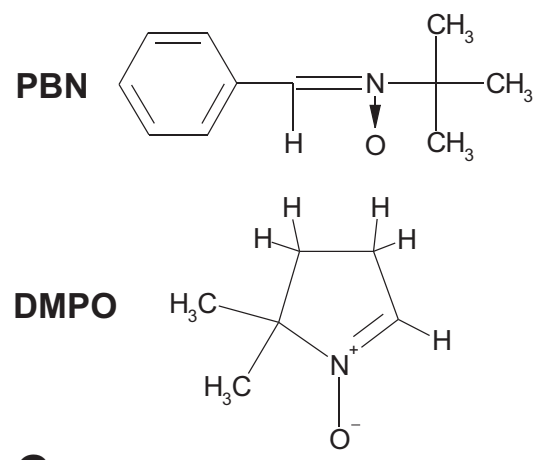

C

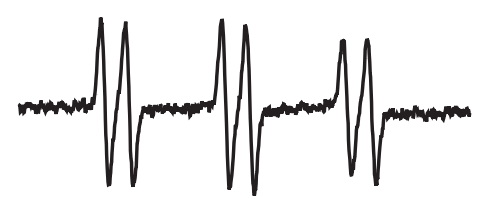

$\begin{array}{llllll}347 & 348 & 349 & 350 & 351 & 352\end{array}$ B [mT]
B

\section{$\mathrm{CPH}$}<smiles>CC1(C)CC(C(=O)O)C(C)(C)N1O</smiles>

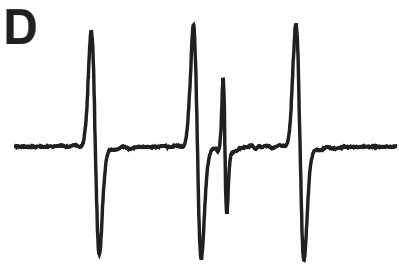

$\begin{array}{lllllll}336 & 337 & 338 & 339 & 340 & 341 & 342\end{array}$

B [mT]

Fig. 3. Selected spin traps and their EPR spectra. Chemical structures of representative nitrone (A) and cyclic hydroxyl amine (B) spin traps together with typical EPR spectra dominated by the interaction of ${ }^{14} \mathrm{~N}$ of the NO-group of the spin adduct (cf. Fig. 2). The signals arise after trapping of carbon centered or OH ${ }^{\bullet}$-radicals by PBN (C), or after oxidation of CPH by superoxide (D). The smaller narrow signal is from a field marker compound. CPH, 1-hydroxy-3-carboxy-2,2,5,5-tetramethylpyrrolidine; DMPO, 5,5-dimethyl-pyrroline N-oxide; PBN, N-tert-butyl- $\alpha$-phenylnitrone.

$\mathrm{O}_{2}{ }^{-} \cdot$ or other oxidants like $\mathrm{OH}^{\bullet}$ yielding in all cases the same typical three line nitroxide spectrum (Fig. 3D) [63]. To distinguish what type of oxidizing species is effective, specific radical scavengers such as SOD for superoxide need to be employed. If the nitroxide signal is persistent, an oxidizing reactant like $\mathrm{OH}^{\bullet}$ or yet another species have to be considered and analysed further.

Summing up, the spin trapping technique provides a useful method to specifically identify radicals in a complex biological system via the spectral pattern of the spin adduct and/or to sensitively quantify the radical formation via the build-up of signal intensity. Ideally, a trap reagent efficiently scavenges generated primary radicals at non-toxic concentration in a biological measurement. The radical product (spin adduct) has to be sufficiently stable; it should not decay spontaneously and should be inert against further reduction or oxidation processes by other radicals or compounds (like ascorbic acid, glutathione etc.) present in the setup. In practice, the usually non-ideal properties of a spin trap in a physiological or medical experiment require well designed control experiments to avoid potential misinterpretations.

Advantages: Very selective for radicals, possibility to distinguish between different primary radicals, intra- and extracellular measurements associated with trap properties and specific radical scavengers, sensitivity in nanomolar range, easy and fast to quantify

Disadvantages: No single cell measurements possible, expensive equipment and need for specialist, short life time of spin adducts may impede radical identification and quantification

\section{Checkpoints for controlling the intracellular $\mathrm{Ca}^{2+}$ concentration}

In virtually all cells, $\mathrm{Ca}^{2+}$ ions have an essential role in the regulation of many signaling cascades and cellular functions [64-66]. While some of these processes can be governed by $\mathrm{Ca}^{2+}$ ions in the extracellular milieu $[67,68]$, most of them are initiated by changes in the intracellular $\mathrm{Ca}^{2+}$ concentration $\left(\left[\mathrm{Ca}^{2+}\right]_{\mathrm{i}}\right)$. The steep $(\sim 10000$ fold) concentration gradient between the basal $\left[\mathrm{Ca}^{2+}\right]_{i}$ and the extracellular $\mathrm{Ca}^{2+}\left(\left[\mathrm{Ca}^{2+}\right]_{0}\right)$, already indicates the importance of constant and tight control of cellular $\mathrm{Ca}^{2+}$ homeostasis. Transient increases in $\left[\mathrm{Ca}^{2+}\right]_{i}$ are the essence of most $\mathrm{Ca}^{2+}$-regulated cellular functions. To fully and precisely control these dynamic changes in $\left[\mathrm{Ca}^{2+}\right]_{i}$, cells require a complex machinery of $\mathrm{Ca}^{2+}$ channels, pumps, transporters and $\mathrm{Ca}^{2+}$ binding proteins. These can be embedded in the plasma membrane, membranes of endoplasmic reticulum(ER), mitochondria and other organelles or are dissolved in the cytosol [64-66].

Major influx pathways for the entry of extracellular $\mathrm{Ca}^{2+}$ into the cytosol include voltage-gated $\mathrm{Ca}^{2+}$ channels (CaV) [69], receptor operated channels (such as transient receptor potential (TRP) channels [70-73] and others) and $\mathrm{Ca}^{2+}$ release-activated $\mathrm{Ca}^{2+}$ (CRAC/Orai) channels [74]. Certain TRP channels are also expressed in membranes of intracellular organelles and may thus be involved in the intracellular $\mathrm{Ca}^{2+}$ handling $[75,76]$.

Because a prolonged increase in $\left[\mathrm{Ca}^{2+}\right]_{i}$ is usually toxic, rapid and regulated transport of $\mathrm{Ca}^{2+}$ out of the cytosol is of vital importance [77]. Ion pumps located within the plasma membrane such as the $\mathrm{Ca}^{2+}$ ATPases (PMCA) are required for efficient $\mathrm{Ca}^{2+}$ extrusion. In addition, the $\mathrm{Na}^{+} / \mathrm{Ca}^{2+}$ exchanger (NCX) and the $\mathrm{Na}^{+} / \mathrm{Ca}^{2+}-\mathrm{K}^{+}$ exchanger (NCKX) also play an important role. Under certain conditions these exchangers can reverse their mode and contribute to an increase of $\left[\mathrm{Ca}^{2+}\right]_{\mathrm{i}}[64-66]$. Besides extruding $\mathrm{Ca}^{2+}$ to the extracellular space, intracellular $\mathrm{Ca}^{2+}$ stores also play an important role in regulating $\mathrm{Ca}^{2+}$ homeostasis. The most prominent stores are the lumen of the ER and the mitochondria.

Within its lumen, ER stores contain $\mathrm{Ca}^{2+}$ at concentration of $\sim 0.5 \mathrm{mM}$, which can be rapidly released into the cytosol through activated inositol 3-phosphate- $\left(\mathrm{IP}_{3} \mathrm{R}\right)$ or ryanodine receptors (RyR) [78-80]. The refilling of these $\mathrm{Ca}^{2+}$ pools is achieved by sarcoendoplasmic reticulum $\mathrm{Ca}^{2+}$ ATPases (SERCA). SERCAs pump $\mathrm{Ca}^{2+}$ back into the ER, as some $\mathrm{Ca}^{2+}$ constantly leaks across the ER membrane [81-85]. The molecular identity of these leak channels is still 
controversial, although recent data points towards the involvement of the Sec61 translocon [86-88].

In mitochondria, $\mathrm{Ca}^{2+}$ ions cycle between the cellular cytosol and the mitochondrial matrix thereby regulating organelle function and ATP production [89-91]. During this process $\mathrm{Ca}^{2+}$ ions have to cross two membranes: the outer- (OMM) and the inner mitochondrial membrane (IMM). It has been proposed that the OMM is porous and therefore does not play a major role in mitochondrial $\mathrm{Ca}^{2+}$ entry. However, some studies suggested that the voltage dependent anion channel (VDAC) might play an important indirect role in the mitochondrial $\mathrm{Ca}^{2+}$ homeostasis [92-94]. Across the IMM, two major transport pathways for $\mathrm{Ca}^{2+}$ ions are proposed. One is activated at relatively high intramembrane space $\mathrm{Ca}^{2+}$ concentration and is underlined by a very selective channel known as the mitochondrial $\mathrm{Ca}^{2+}$ uniporter (MCU). The second pathway has much lower capacity but higher $\mathrm{Ca}^{2+}$ sensitivity and is probably governed by several channels or transporters [95].

Very recently, two groups identified an IMM-based, twotransmembrane domains containing protein known as CCDC109A as a pore forming unit of $\mathrm{MCU}$, which is a great advance in the field of mitochondrial $\mathrm{Ca}^{2+}$ regulation. However, the orientation of the protein in the membrane and its role either as a bona fide ion channel or as part of a larger protein complex still needs to be clarified [96,97]. In addition, an IMM protein known as Letm1 has been shown to act as an efficient $\mathrm{Ca}^{2+} / \mathrm{H}^{+}$exchanger leading to an increase in the $\mathrm{Ca}^{2+}$ concentration or the mitochondrial matrix [98]. We have also shown that hydroxylated coenzyme $\mathrm{Q}(\mathrm{CoQ})$ forms (present at the IMM) are able to transport $\mathrm{Ca}^{2+}$ across artificial membranes but if and how these CoQs affect the mitochondrial $\mathrm{Ca}^{2+}$ homeostasis is not yet clear $[99,100]$. Given the biophysical properties of $\mathrm{Ca}^{2+}$ transport by Letm 1 and hydroxyl CoQs, it is possible that they are involved in the slow mitochondrial $\mathrm{Ca}^{2+}$ uptake.

To remove $\mathrm{Ca}^{2+}$ from the mitochondrial matrix and prevent $\mathrm{Ca}^{2+}$ overload and subsequent pathological conditions the $\mathrm{Na}^{+} / \mathrm{Ca}^{2+}$ exchanger is essential [90]. Similar as for $\mathrm{Ca}^{2+}$ import, some reports suggest a role for the mitochondrial permeability transition pore (mPTP) and the OMM for mitochondrial $\mathrm{Ca}^{2+}$ efflux [101].

Obviously, many of the $\mathrm{Ca}^{2+}$ transport and binding processes are now understood on the molecular level. This is one prerequisite to understand their interplay to control the $\mathrm{Ca}^{2+}$ homeostasis during cell activation. ROS modulate many transporters and are therefore involved in the modulation of $\mathrm{Ca}^{2+}$ homeostasis (Fig. 4).

\section{Effects of ROS on ion channels}

\subsection{General mechanisms of protein oxidation}

While ROS can react with nuclear DNA, lipids of the cellular membranes and with polypeptides, it is mainly their action on proteins that endows them with specificity. The wide range of cellular functions that are regulated by ROS signaling include - among others - growth factor responses, cell adhesion and apoptosis, and depend on specific and reversible modification of the proteins involved in the related signaling cascades [2]. A

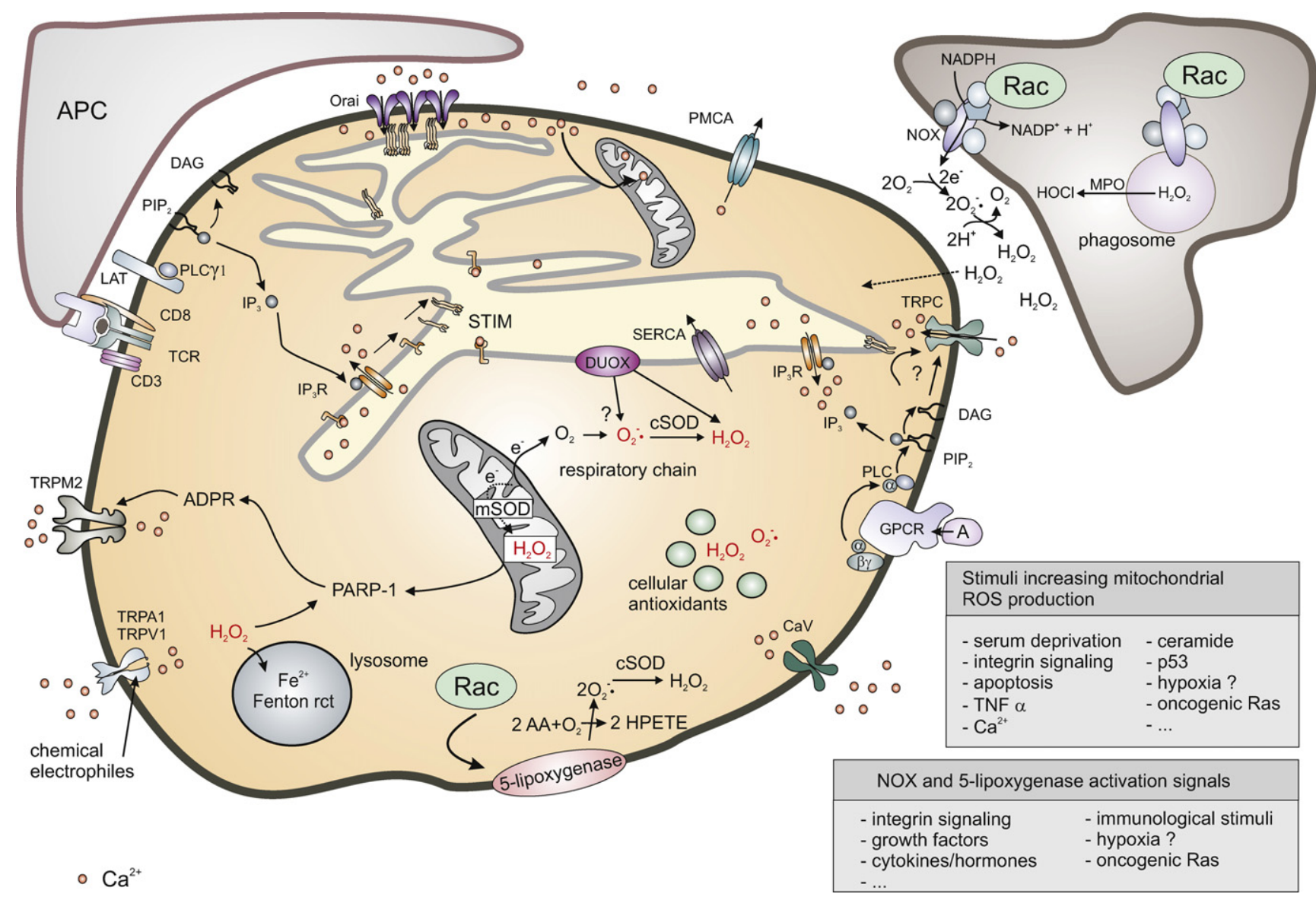

Fig. 4. Redox and $\mathrm{Ca}^{2+}$ signaling pathways. A, agonist; APC, antigen presenting cell; CD, cluster of differentiation; DAG, diacylglycerol; DUOX, dual oxidase; GPCR, G proteincoupled receptor; $\mathrm{IP}_{3}$, inositol 1,4,5-trisphosphate; $\mathrm{IP}_{3} \mathrm{R}$, IP $\mathrm{IP}_{3}$ receptor; LAT, linker of activated T cells; MPO, myeloperoxidase; PARP-1, poly-(ADP-ribose)-polymerase; PIP 2 , phosphatidylinositol 4,5-bisphosphate; PLC, phospholipase C; PMCA, plasma membrane calcium ATPase; SERCA, sarco-endoplasmic reticulum ATPase; STIM, stromal interaction molecule; TRP, transient receptor potential; cSOD, cytoplasmic superoxide dismutase; mSOD, mitochondrial superoxide dismutase; ADPR, ADP-ribose; AA, arachidonic acid; HPETE, hydroperoxyeicosatetraenoic acid; VOC channel, voltage operated calcium channel; NOX, NADPH oxidase; NADP, nicotinamide adenine dinucleotide phosphate. 
well-studied example is the response of $E$. coli to oxidative stress: the oxidation of two-SH groups by increasing concentrations of $\mathrm{H}_{2} \mathrm{O}_{2}$ leads to reversible formation of a disulphide bond within the transcription factor oxyR, thereby activating the expression of several antioxidative enzymes, which protect $E$. coli against increased levels of oxidative stress [102,103].

High concentrations of ROS can cause a wide range of amino acid modifications, e.g. the oxidation of thiol groups to sulfenic, sulfinic and sulfonic acids, the oxidation of arginine and lysine residues to aldehydes or of methionine to the corresponding sulphoxide or sulphone. Oxidation can also lead to intra- and intermolecular crosslinking and trapping of proteins in multimolecular complexes. Many of those modifications are essentially irreversible, abolish protein function and eventually lead to degradation. On the contrary, physiologically relevant concentrations of ROS can react with specific regulatory amino acids within the polypeptide chain. This selective action depends on the accessibility within the tertiary structure, the local concentration and nature of the reacting redox species and on the local redox potential. While redox signaling regulates the function of an array of proteins ranging from transcription factors to protein kinases and phosphatases [2,14,104-106], we will focus here on $\mathrm{Ca}^{2+}$ conducting ion channels, in particular voltage-gated $\mathrm{Ca}^{2+}$ channels, the TRP superfamily and CRAC/Orai channels.

\subsection{Voltage-gated $\mathrm{Ca}^{2+}$ channels}

The voltage-gated $\mathrm{Ca}^{2+}$ channel (CaV) family consists of 5 major subgroups known as L-type- (Cav1.1-1.4), N-type- (Cav2.2), P/Qtype- (Cav2.1), R-type- (Cav2.3), and T-type- (Cav3.1-3.3) $\mathrm{Ca}^{2+}$ channels. They are expressed in many cell types and are responsible for various cellular functions such as muscle contraction, control of action potential, secretion, gene expression and others. Because both redox- and $\mathrm{Ca}^{2+}$-signaling play an important role in the cardiovascular system, where $\mathrm{CaV}$ channels are highly expressed, they were one of the first $\mathrm{Ca}^{2+}$ channels to be identified as redox sensitive.

In a number of studies a large variety of oxidants have been found to regulate CaV channel activity on different levels, affecting their expression, trafficking, open time and open probability. Some of these studies could demonstrate that reactive cysteines in the pore-forming $\alpha 1$-subunit are the molecular targets for ROS. $\mathrm{CaV}$ channel redox regulation has been studied in myocytes and neurons of various species as well as in heterologous expression systems. Similar as for the reports on redox regulation of Orai as well as for some TRP channels (see below), some authors described activation of $\mathrm{CaV}$ by oxidation while others reported the contrary, i.e. inhibition of channel activity.

These differences may depend on the cell type and genetic modulation (endogenous channels or an over-expressing system) but also point towards a complex redox regulation of $\mathrm{Ca}^{2+}$ signaling in the cardiovascular and nervous system where oxidation of additional targets could influence $\mathrm{CaV}$ channel function.

The findings regarding the redox regulation of $\mathrm{CaV}$ channels are summarized in Table 1 and have been described elsewhere in detail [107-109].

\subsection{TRP channels}

Members of the mammalian transient receptor potential (TRP) family of ion channels are subdivided into seven subgroups according to sequence homologies and protein domains (TRPC, TRPM, TRPV, TRPA, TRPN, TRPP and TRPML). The canonical or "classical" TRPC members share the highest degree of sequence homology to the founding member Drosophila TRP. TRP channels are cation-permeable and are involved in the detection of differ- ent sensory modalities. Their activating mechanisms include direct detection of temperature and/or chemical compounds, extra/intracellular ion concentrations but also detection of second messengers generated by G-protein coupled receptors (GPCR) cascades. The expression pattern of TRP channels range from ubiquitously expressed (i.e. TRPM7) to very restricted expression in specialized cells $[71,110,111]$. While all cells can be exposed to intracellular ROS, exposure to extracellular ROS generated by environmental factors such as UV light or chemical irritants or by specialized ROS-producing cells, such as monocyte derived cells, granulocytes and thyroid cells depends on localization. Cells and tissues in the immediate vicinity of the ROS source will obviously be affected more than others.

Regarding regulation of ion channels by oxidation, TRPM2 channels have been most extensively investigated (see below and Table 2), however, other TRP channels such as TRPV1 and TRPA1, expressed in sensory neurons mediating responses to irritant substances such as pungent and electrophilic compounds found in chili peppers, mustard oil, onions, garlic and cinnamon extracts [112-117], are also excellent targets for investigation of cysteine modifications. Indeed, pain related behavior relayed by TRPA 1 in wildtype but not in TRPA1 -/- mice can be aggravated by irritant, oxidizing compounds such as allicin and diallyl disulfide (DADS), but also by $\mathrm{H}_{2} \mathrm{~S}$ and $\mathrm{H}_{2} \mathrm{O}_{2}[114,118,119]$. In an effort to identify the targets of the electrophilic attack in heterologous expression systems, two independent groups used cysteine mutagenesis studies. Hinman et al. [120] identified three critical cysteine residues (C621, C641, and $\mathrm{C}_{665^{*}}$ ) downstream of the ankyrin repeat region of human TRPA1 as being critical in conferring sensitivity towards $N$ methylmaleimide (NMM), although the mutant retained a residual sensitivity towards allyl isothiocyanate (AITC), which was annulled by further mutation of K710 [120], ( ${ }^{*}$ note: the original report has $\mathrm{a}-2$ shift in the amino acid nomenclature). In a parallel study, Macpherson et al. [121] used click chemistry and mass spectrometry to identify 14 cysteines that can be modified by iodoacetamide (IA); three of which (C415, C422 and C622, mouse TRPA1) are critical for mediating the activating effect of mustard oil on channel function. Cysteine 622 (mTRPA1) is identical to C621 (hTRPA1) and is conserved in TRPA 1 clade members with the exception of Ciona intestinales, as also C622, C415, C422, C642 and K712 (mTRPA1), suggesting an ancient shared origin of chemical nociception [122].

In the case of the capsaicin receptor TRPV1, allicin, one of the active compounds in garlic and onions, was found to sensitize TRPV1. In a thorough analysis of the actions of allicin on TRPV1, Salazar et al. [123] found that, in contrast to TRPA1 channels, modification of only a single cysteine (C157) located in the N-terminal region of TRPV1 was necessary and sufficient to mediate the activating effect of allicin or MTSEA. Interestingly, in both TRPA1 and TRPV1 the modified cysteines are localized in cytosolic regions of the proteins, thus require the electrophilic compounds to cross the plasma membrane. Besides the likely physiological role of these cysteine modifications in the sensation of the burning feeling of spicy foods, oxidant (reactive electrophiles) induced modification of TRPA1 residues plays an important role in the chemical nociception of toxic compounds (e.g. during cigarette smoking) and represents an evolutionary ancient detection system [122]. TRPA1 is thus also an attractive candidate for the development of drugs to reduce pain and inflammation associated with airway inflammation.

\subsubsection{Redox activation of TRP channels in cell death}

The best studied target for ROS induced cell death in mammals is TRPM2, a ubiquitously expressed member of the TRPM family. A very recent and detailed review describes the role of TRPM2 in oxidative stress [124], thus we will only provide a brief summary here. TRPM2 is a non-selective cation channel with a permeability of $\mathrm{Na}^{+}>\mathrm{Ca}^{2+}>\mathrm{K}^{+}$and is activated by cADPR, ADPR and 
Table 1

Redox regulation of voltage gated calcium channels.

\begin{tabular}{|c|c|c|c|c|c|}
\hline & Cells & Redox modulator & Effect & Target & Ref. \\
\hline \multirow[t]{2}{*}{ L-type } & $\begin{array}{l}\text { HEK, rat myocytes guinea } \\
\text { pig, myocytes, frog } \\
\text { myocytes, PC12, neurons }\end{array}$ & $\begin{array}{l}\text { PHMPS, thimerosal, } 2.3 \mathrm{mM} \text { purine }+20 \mathrm{U} / 1 \mathrm{XO} \text {, } \\
\text { DHF, ascorbate } / \mathrm{Fe}^{2+}, \text { PCMBS, MTSEA, DTNB, } \\
\mathrm{X} / \mathrm{XO} \text {, Endogenous ROS, Hypoxia, } \mathrm{H}_{2} \mathrm{O}_{2}\end{array}$ & $\uparrow \mathrm{Ca}^{2+}$ currents & $\begin{array}{l}\text { cysteine oxidation, increased } \\
\text { trafficking, upregulation of } \\
\text { channel expression }\end{array}$ & [219-223] \\
\hline & $\begin{array}{l}\text { HEK, CHO, rat myocytes, } \\
\text { guinea pig myocytes, } \\
\text { arterial myocytes, chick } \\
\text { retinal cells }\end{array}$ & $\begin{array}{l}\mathrm{H}_{2} \mathrm{O}_{2} \text {, MTSEA, MTSET, PHMPS, DTDP, DTBNP, } \\
2,2^{\prime} \text {-dithiodipyridine thimerosal, SIN- } 1 \text {, DTNB, } \\
\mathrm{H}_{2} \mathrm{O}_{2} / \mathrm{Fe}^{3+} \text {, hypoxia, } \mathrm{CO} \text {, endogenous ROS, } \\
\text { CORM-2 }\end{array}$ & $\downarrow \mathrm{Ca}^{2+}$ currents & $\begin{array}{l}\text { cysteine oxidation, } \mathrm{C} 1789 \text {, } \\
\text { C1790, } 1810 \text { on } \alpha 1 C \text {, } \\
\text { reduction in dihydropyridine } \\
\text { binding sites, reduced } \\
\text { sensitivity towards } \\
\text { physiological stimulation, } \\
\text { changes in PM potential }\end{array}$ & [224-232] \\
\hline T-type & $\begin{array}{l}\text { HEK, rat neurons } \\
\text { HEK, rat neurons, rat } \\
\text { peripheral nociceptors }\end{array}$ & $\begin{array}{l}\text { GSH, DTNB, L-cysteine, DTT, TCEP } \\
\text { GSSG, MTSET }\end{array}$ & $\begin{array}{l}\uparrow \mathrm{Ca}^{2+} \text { currents } \\
\downarrow \mathrm{Ca}^{2+} \text { currents }\end{array}$ & extracellular cysteines & [233-237] \\
\hline P/Q-type & xenopus oocytes & $\mathrm{H}_{2} \mathrm{O}_{2}$, DTNB & $\begin{array}{l}\downarrow \mathrm{Ca}^{2+} \text { currents } \\
\uparrow \mathrm{Ca}^{2+} \text { currents } \\
\text { at positive } \\
\text { potentials }\end{array}$ & ND & [238] \\
\hline
\end{tabular}

CHO, chinese hamster ovary; CORM-2, tricarbonyl dichloro ruthenium(II) dimer (CO donor); DHF, dihydroxyfumaric acid; DTBNP, 2,2'-dithiobis(5-nitropyridine); DTDP, 2,2'-dithiodipyridine; DTNB, 5,5'-dithiobis[2-nitrobenzoic acid]; DTT, dithiothreitol; GSH, glutathione; GSSG, glutathione disulfide; HEK, human embryonic kidney; MTSEA, 2-aminoethyl methanethiosulfonate hydrobromide; MTSES, sodium (2-sulfonatoethyl) methanethiosulfonate; MTSET, [2-(Trimethylammonium)ethyl] methanethiosulfonate bromide; PCMBS, p-chloromercuribenzene sulphonic acid; PHMPS, p-hydroxy-mercuric-phenylsulphonic acid; SIN-1, linsidomine (NO donor); TCEP, tris(2-carboxyethyl)phosphine; X, xanthine; XO, xanthine oxidase.

NAADP [73,125-127]. Mori and coworkers first described activation by addition of $\mathrm{H}_{2} \mathrm{O}_{2}$, leading to cell death [128]. Interestingly, ROS mediated activation of TRPM2 is not a direct effect, but is mediated by an increased mitochondrial synthesis of the TRPM2 ligand ADP-Ribose [129] as well as an increased ADP-ribose synthesis by the nuclear enzyme poly-(ADP-ribose)-polymerase PARP-1, no oxidant-induced activation of TRPM2 is detected in PARP-1 deficient cells [130]. In monocytes, which are able to produce significant amounts of $\mathrm{H}_{2} \mathrm{O}_{2}$ through NOX2, activation of TRPM2 triggers an Erk mediated pathway that ultimately leads to enhanced transcription of CXCL8, a chemokine that leads to neutrophil infiltration at sites of inflammation. TRPM2 knock-out mice are protected against this infiltration and show reduced inflammation in a mouse model of colitis ulcerosa [131]. Neurons also express TRPM2 where it may be involved in $\mathrm{H}_{2} \mathrm{O}_{2}$-induced neuronal death [132,133].
In contrast to oxidant-induced activation of the $\mathrm{Ca}^{2+}$ permeable TRPM2 which leads to apoptosis, a recent report describes redox dependent facilitation of TRPM4 currents by $\mathrm{H}_{2} \mathrm{O}_{2}$ which can ultimately lead to cell death by necrosis. Down regulation of TRPM4 in HeLa cells prevented $\mathrm{H}_{2} \mathrm{O}_{2}$ induced necrotic cell death while leaving apoptotic pathways intact [134]. In contrast to all other TRP channels, TRPM4 and TRPM5 are monovalentselective cation channels that are $\mathrm{Ca}^{2+}$ activated and likely regulate membrane potential $[135,136]$. Because both TRPM2 and TRPM4 are activated or facilitated in a similar concentration range of $\mathrm{H}_{2} \mathrm{O}_{2}\left(\mathrm{EC}_{50} \sim 50 \mu \mathrm{M}\right)$, relative expression levels of these channels, of PARP-1 and of intracellular antioxidant proteins might determine whether and when cells undergo oxidant induced apoptosis versus necrosis. While TRPM2 oxidant induced activation is indirect, hTRPM4 is directly modulated by oxidation of a C-terminally

Table 2

Redox regulation of TRPM, TRPA and TRPV channels.

\begin{tabular}{|c|c|c|c|c|c|}
\hline Channel & Cells & Redox modulator & Effect & Target & Ref. \\
\hline TRPM2 & $\begin{array}{l}\text { HEK, neurons, } \\
\text { microglia, A172, } \\
\text { vascular endothelial } \\
\text { cells }\end{array}$ & $\begin{array}{l}\mathrm{H}_{2} \mathrm{O}_{2} \text { 0.1-5 mM, } \\
\text { nitrosothiol donor } \\
\text { MNNG } 10 \mu \mathrm{M}\end{array}$ & $\begin{array}{l}\uparrow \mathrm{Ca}^{2+}, \mathrm{Na}^{+} \text {influx, } \\
\text { currents } \\
\uparrow \text { apoptotic cell death }\end{array}$ & $\begin{array}{l}\text { no direct target, increased } \\
\text { production of ADPR } \\
\text { (mitochondria) }\end{array}$ & $\begin{array}{l}{[128-130],[132]} \\
{[239-243]}\end{array}$ \\
\hline TRPM4 & HEK, HELA & $\mathrm{H}_{2} \mathrm{O}_{2} 0.2 \mathrm{mM}$ & $\begin{array}{l}\uparrow \mathrm{Ca}^{2+}, \mathrm{Na}^{+} \text {influx } \\
\text { desensitization } \\
\uparrow \text { necrotic cell death }\end{array}$ & $\begin{array}{l}\text { direct, target intracellular } \\
\text { C1093 }\end{array}$ & [134] \\
\hline TRPM6 & HEK & $\mathrm{H}_{2} \mathrm{O}_{2} 1 \mathrm{mM}$ & $\downarrow$ outward current & $\begin{array}{l}\text { direct, blocked by intracell. } \\
\text { interaction with MsrB1 } \\
\text { M1755 }\end{array}$ & {$[244]$} \\
\hline TRPM7 & HEK, neurons & $\begin{array}{l}\text { OGD, NaCN, } \mathrm{H}_{2} \mathrm{O}_{2} \text {, } \\
\text { menadione, NO }\end{array}$ & $\begin{array}{l}\uparrow \text { inward } \mathrm{Ca}^{2+}, \mathrm{Na}^{+} \\
\text {current } \\
\downarrow \text { outward current }\end{array}$ & $\begin{array}{l}\text { no direct effect, activity of } \\
\text { TRPM7 increases ROS } \\
\text { production }\end{array}$ & [143] \\
\hline TRPA1 & $\begin{array}{l}\text { HEK, C-neurons WT/KO } \\
\text { mice bladder }\end{array}$ & $\begin{array}{l}\mathrm{H}_{2} \mathrm{O}_{2}\left(\mathrm{EC}_{50} \sim 230 \mu \mathrm{M}\right) \text {, } \\
\text { AITC, NMM, mustard } \\
\text { oil, MTSEA, MTSET, AI, } \\
\text { CA, NaHS }\end{array}$ & $\uparrow \mathrm{Ca}^{2+}, \mathrm{Na}^{+}$current & $\begin{array}{l}\text { direct, intracellular } \\
\text { C415, C422, C622 } \\
\text { C619, C639, C663, K708 }\end{array}$ & $\begin{array}{l}{[117-121]} \\
{[245-247]}\end{array}$ \\
\hline \multirow[t]{2}{*}{ TRPV1 } & $\begin{array}{l}\text { sensory neurons, } \\
\text { WT/KO mice, HEK, } \\
\text { Het1A }\end{array}$ & $\begin{array}{l}\text { thimerosal, } \\
\mathrm{H}_{2} \mathrm{O}_{2} 1 \mathrm{mM}\end{array}$ & $\downarrow \mathrm{Ca}^{2+}, \mathrm{Na}^{+}$current & $\begin{array}{l}\text { extracellular: C621 } \\
\text { G.g. specific: C66, C111, C832 }\end{array}$ & {$[123,246,248,249]$} \\
\hline & & $\begin{array}{l}\mathrm{H}_{2} \mathrm{O}_{2} 1 \mathrm{mM} \text {, allicin, } \\
\text { MTSEA, HNE }\end{array}$ & $\uparrow \mathrm{Ca}^{2+}, \mathrm{Na}^{+}$current & $\begin{array}{l}\text { direct intracellular } \\
\text { C157, G.g.: C783 }\end{array}$ & {$[248,250]$} \\
\hline
\end{tabular}

A172, human glioblastoma cell line; AI, allyl isothiocyanate; AITC, allyl isothiocyanate; CA, cinnamaldehyde; HEK, human embryonic kidney; HeLa, human andenocarcinoma cell line; Het1A, human epithelial cell line (esophagus); HNE, 4-hydroxy-2-nonenal; MNNG, $N$-Methyl- $N$ '-nitrosoguanidine; MTSEA, 2-aminoethyl methanethiosulfonate hydrobromide; MTSET, [2-(Trimethylammonium)ethyl] methanethiosulfonate bromide; NMM, $N$-methylmaleimide; OGD, oxygen glucose deprivation 
located cysteine, C1093 (see Table 1). This cysteine residue is conserved in TRPM3, 6 and 7, although its role has not been investigated within these channels.

TRPM6 and TRPM7 are both unusual members of the TRP family as they possess both ion channel and protein kinase activities. These serine/threonine kinase domains are located at the extreme $\mathrm{C}$ terminus, but their activity does not directly affect channel function, although autophosphorylation has been demonstrated for TRPM7 [137]. Both channels are divalent selective, allowing entry of $\mathrm{Mg}^{2+}$ and $\mathrm{Ca}^{2+}$, but will be inhibited by intracellular $\mathrm{Mg}^{2+}(0.3-1 \mathrm{mM})$ $[138,139]$. While TRPM7 is ubiquitously expressed and essential for $\mathrm{Mg}^{2+}$ homeostasis and cell survival, TRPM6 is strongly expressed in kidney and intestine where it also plays an important role in epithelial $\mathrm{Mg}^{2+}$ reabsorption [140,141]. TRPM6 interacts through its alpha-kinase domain with methionine sulfoxide reductase B1 (MsrB1). This protein interaction is able to mask the inhibitory effect of $\mathrm{H}_{2} \mathrm{O}_{2}$ on channel activity. Mutation of methionine 1755 within the kinase domain was able to reduce the inhibitory effect of $\mathrm{H}_{2} \mathrm{O}_{2}$, thereby mimicking the action of MsrB1. Reversible oxidation of methionine residues is a relatively novel concept in ion channel physiology. Methionine oxidation has been reported to disrupt inactivation of shaker voltage-dependent $\mathrm{K}^{+}$channel activity, an effect that can be reversed upon coexpression with MsrA1 [142]. Whether a similar mechanism can occur in TRPM7 is unknown. On the contrary, suppression of TRPM7 expression reduced cell death induced by prolonged oxygen glucose deprivation (OGD) in neuronal cultures. OGD activated $\mathrm{Ca}^{2+}$ permeable non-selective currents that resemble those of heterologously expressed TRPM7. The authors demonstrated enhanced inward currents in $\mathrm{H}_{2} \mathrm{O}_{2}$ ( $1 \mathrm{mM}$ ) stimulated TRPM7 expressing HEK cells [143]. A finding that several independent siRNA approaches to reduce TRPM7 in neurons also decreased expression of TRPM2 mRNA, raised the possibility that TRPM7 and TRPM2 expression are interdependent, thus further complicating the analysis of the effects of oxidative stress on native cells. A summary of redox regulation of TRPM2, $-4,-6,-7$, $\mathrm{A} 1$ and $\mathrm{V} 1$ channels is given in Table 2

\subsubsection{Redox regulation of TRPC channels}

We will only briefly summarize the effects of ROS on TRPC channels as several reviews recently summarized the existing data [144-147]. One of the earliest reports on redox regulation of TRP channels by the Groschner group reports regulation of TRPC 3 by the oxidant tBHP (tert-butylhydroperoxide). tBHP increases cation currents in porcine aortic endothelial cells, an effect that has also been observed in cells overexpressing TRPC3 or TRPC4 channels [148]. The subsequent finding that the activating effect of oxidants in TRPC3 expressing cells can be inhibited by the U73122, an inhibitor of phospholipase C (PLC) [149], might suggest that activation does not involve direct oxidation of thiols in TRPC proteins, although a required costimulatory role of phospholipids such as diacylglycerol (DAG) together with a direct oxidant effect cannot be ruled out. Because ROS are known to inhibit protein phosphatases such as PP2A, the effects of increased ion channel phosphorylation versus a direct oxidation of ion channel thiol-groups need to be taken into account.

A further complication in the analysis of reactive cysteines results from the cross-talk between the oxidation of cysteines by ROS and cysteine S-nitrosylation by nitric oxide. Mild (reversible) oxidation as well as rapid and highly instable formation of Snitrosylated cysteines by NO which can be generated by hypoxic conditions or through activation of cellular nitric oxide synthase (NOS) may be viewed as a posttranslational modification such as phosphorylation. In a comprehensive investigation the role of nitric oxide (NO) and $\mathrm{H}_{2} \mathrm{O}_{2}$ on TRP channels was analysed [150]: The receptor operated TRP channels (TRPC5 and C7) as well as the thermo-sensitive TRPV channels (TRPV1, V3 and V4) all increased
$\mathrm{Ca}^{2+}$ entry into cells in response to the NO donor SNAP, an effect which is partially reversed by additional application of the reducing agent DTT. The effect is mediated by cysteine S-nitrosylation of the conserved cytoplasmatically accessible C553 and C558 of the H7 pore loop region between S5 and S6 of TRPC5 likely bending the S6 segment to open the intracellular activation gate. The membranepermeable thiol-reactive compound MTSEA can mimic this effect, but not the membrane-impermeable MTSET. Similar effects of NO can be seen for TRPV1, TRPV3 and TRPV4 that contain cysteines within the same region. In addition, Yoshida et al. showed that TRPC5 is activated by $\mathrm{H}_{2} \mathrm{O}_{2}$ as well [150]. Another study investigated the effects of the intracellular and secreted redox active protein thioredoxin on TRPC5 channel function. The authors report that extracellular application of reduced thioredoxin as well as of DTT can activate TRPC5 by breaking an existing disulfide bridge between C553 and C558 [151], which generates a discrepancy as to how accessible these cysteines in the S5-S6 linker region are towards either the intra-or extracellular side. The combined groups of Yao and Beech were unable to reproduce the $\mathrm{H}_{2} \mathrm{O}_{2}$-mediated activation of TRPC5 [152]. However, in a recent publication, the Beech group did indeed show TRPC5 activation by $\mathrm{H}_{2} \mathrm{O}_{2}$, an effect that was suppressed by exogenous anti-oxidants [153]. Considering the results discussed above, it would be interesting to investigate if the pore loop exists as an unstable equilibrium between reduced (redox sensitive) C553 and C558 and a disulfide bonded C553 with C558, thus allowing the pore to adjust to different oxidative environments, which depending on culture and recording conditions, may yield diverging results as to their redox sensitivity. A summary of redox regulation of TRPC channels is given in Table 3.

\subsection{Store operated $\mathrm{Ca}^{2+}$ entry (SOCE) and CRAC/Orai channels}

The concept of store operated $\mathrm{Ca}^{2+}$ entry (SOCE) was first proposed by Jim Putney in the mid eighties [154,155]. Soon afterwards, several seminal papers described signaling events underlying SOCE and the biophysical properties of the $\mathrm{Ca}^{2+}$ channel itself. The channel was named $\mathrm{Ca}^{2+}$ release activated $\mathrm{Ca}^{2+}(\mathrm{CRAC})$ channel with the ion current described as $\left(I_{C R A C}\right)$ [156-158]. The molecular identity of the CRAC channels was not known until 2006 when three independent groups identified the pore forming protein [159-161]. Besides the major component Orai1 (CRACM1), which when mutated (R91W) leads to severe combined immune deficiency (SCID) [159], two homologs, namely Orai2 and Orai3 have been identified. Their physiological function is much less defined. Orai homologs can be activated by the $\mathrm{Ca}^{2+}$ sensing ER-proteins STIM1 and STIM2, which were already identified as necessary for activation of SOCE [162-164]. The signaling cascade underlying SOCE thus spans from receptor mediated activation of PLC, hydrolysis of phosphatidylinositol 4,5-bisphosphate with subsequent $\mathrm{IP}_{3}$ production, $\mathrm{IP}_{3} \mathrm{R}$ mediated depletion of $\mathrm{ER} \mathrm{Ca}^{2+}$ stores which in turn leads to a conformational change, oligomerization and translocation of STIM1 to plasma membrane near regions of the ER where STIM1 activates Orai channels through direct interaction with its C-terminal region (Fig. 4). A number of groups have also reported the participation of TRPC1 and TRPC3 in a STIM mediated storeoperated $\mathrm{Ca}^{2+}$ entry pathway, so caution is needed when analyzing native SOCE in the absence of the clearly identified molecular components $[165,166]$.

Redox modification of any of these components may ultimately result in alterations in SOCE. Moreover, STIM1-induced modulation of TRP or voltage-gated $\mathrm{Ca}^{2+}$ channel $[167,168]$ activity may further complicate analyses of ROS mediated effects. Also to be taken into consideration are indirect effects such as ROS mediated activation of cation channels which depolarize the PM and thus lead to indirect modulation of CRAC channel activity by reducing the driving force for $\mathrm{Ca}^{2+}$ influx or the influence of altered phosphorylation of SOCE 
Table 3

Redox regulation of TRPC channels.

\begin{tabular}{|c|c|c|c|c|c|}
\hline Channel & Cells & Redox modulator & Effect & Target & Ref. \\
\hline TRPC3 & ECAP & tBHP $0.4 \mathrm{mM}$ & $\uparrow \mathrm{Na}^{+}$influx & ND, blocked by La ${ }^{3+}$ & [148] \\
\hline TRPC5TRPC5_C1(TRPC7TRPM2) & $\begin{array}{l}\text { HEK, endothelial } \\
\text { cells, VSMC, BAEC }\end{array}$ & $\begin{array}{l}\mathrm{SNAP} 0.3 \mathrm{mM}, \mathrm{H}_{2} \mathrm{O}_{2} \\
1 \mathrm{mM} \text {, oxidized phospholipids, } \\
\text { thioredoxin, DTT } 10 \mathrm{mM}\end{array}$ & $\begin{array}{l}\uparrow \mathrm{Na}^{+}, \mathrm{Ca}^{2+} \text { influx } \\
\uparrow \mathrm{Na}^{+}, \mathrm{Ca}^{2+} \text { influx upon } \\
\text { disulfide bond } \\
\text { breakage }\end{array}$ & $\begin{array}{l}\text { direct, S-Nitrosyl. } \\
\text { C553, C558 } \\
\text { direct target } \\
\text { S-S bond } \\
\text { C553-C558 }\end{array}$ & {$[150-153]$} \\
\hline TRPC6 & $\begin{array}{l}\text { HEK, } \\
\text { kidney glomeruli }\end{array}$ & $\begin{array}{l}\text { PAN (NOX activator), } \mathrm{H}_{2} \mathrm{O}_{2} \\
\mathrm{EC}_{50} \sim 50 \mu \mathrm{M}, \mathrm{NEM} \text {, thimerosal }\end{array}$ & $\begin{array}{l}\uparrow \mathrm{Na}^{+}, \mathrm{Ca}^{2+} \text { influx } \\
\uparrow \text { expression }\end{array}$ & $\begin{array}{l}\text { ND } \\
\text { indirect, no effect on } \\
\text { single channel }\end{array}$ & {$[251,252]$} \\
\hline
\end{tabular}

BAEC, bovine aortic endothelial cells; DTT, dithiothreitol; ECAP, porcine aortic endothelial cells; HEK, human embryonic kidney; NEM, $N$-ethylmaleimide; PAN, puromycin aminonucleoside; SNAP, S-nitroso- $N$-acetyl-DL-penicillamine (NO donor); tBHP, tert-butylhydroperoxide; VSMC, vascular smooth muscle cells.

proteins. The activity of $\mathrm{Ca}^{2+}$ pumps (PMCA) are also affected by oxidation, although at higher concentrations of oxidants and also depending on the cell type $[169,170]$.

\subsubsection{Reactive oxygen species effects on SOCE and CRAC/ORAI channels}

The first indications that redox processes could affect SOCE were reported when thiol group modifying agents, such as thimerosal, were shown to sensitize the $\mathrm{IP}_{3} \mathrm{R}$ but also induce $\mathrm{I}_{\mathrm{CRAC}}$ independently of $\mathrm{IP}_{3}$ [171-174]. These findings were followed by several studies leading to the conclusion that oxidation of $\mathrm{IP}_{3} \mathrm{R}$ and RyR induces their activation and thus lead to depletion of the ER $\mathrm{Ca}^{2+}$ stores (for more details see $[107,108]$ and Table 4 ). On the other hand, there are few studies reporting redox regulation of SOCE independently of $\mathrm{IP}_{3} \mathrm{R}$ or RyR. Elliot et al. [175] describe a complex and time dependent effect of the oxidizing agent tBHP $(0.4 \mathrm{mM})$ on $\mathrm{Ca}^{2+}$ signaling in endothelial cells. They show that short incubation with tBHP (less than $1 \mathrm{~h}$ ) neither affected the induced $\mathrm{ER} \mathrm{Ca}^{2+}$ store content nor its depletion but suppressed SOCE. Longer incubation times (1-2 $\mathrm{h}$ ) reduced store depletion in addition to causing SOCE inhibition, whereas more than $2 \mathrm{~h}$ tBHP incubation induced higher basal $\left[\mathrm{Ca}^{2+}\right]_{i}$ and also a prolonged $\mathrm{Ca}^{2+}$-signal following SOCE activation. Several years later Törnquist et al. confirmed the finding that SOCE is inhibited by thiol-modifying oxidizing agents such as thimerosal, tBHP and $\mathrm{H}_{2} \mathrm{O}_{2}(300 \mu \mathrm{M})$. However, their results suggest that these effects are mediated through activation of protein kinase $C(P K C)[176,177]$. Vanadate and its derivative pervanadate obtained from a chemical reaction with $\mathrm{H}_{2} \mathrm{O}_{2}$ are well established as thiol modifying agents and also implicated in modulating SOCE. However, these compounds are also very potent phosphatase inhibitors and oxidants could thus regulate SOCE via increased phosphorylation. Indeed, several studies showed that maintenance of SOCE can be modulated by redox induced changes in phosphorylation $[14,178,179]$. On the other hand, Ehring et al. reported that vanadate compounds act in a similar way as thimerosal: They deplete the ER $\mathrm{Ca}^{2+}$ stores via thiol oxidation and thus induce activation of $\mathrm{I}_{\text {CRAC }}$ independently of any kinases or phosphatases [180]. Additional evidence that SOCE is inhibited by oxidizing agents such as homocysteine, $\mathrm{H}_{2} \mathrm{O}_{2}, \mathrm{HOCl}$, $\mathrm{tBHP}$ and diamide was later provided by several independent groups in different cell types [181-184]. Particularly interesting are the findings by Redondo et al. who observed modest activation of SOCE following treatment with low $\mu \mathrm{M}$ concentrations of $\mathrm{H}_{2} \mathrm{O}_{2}$ while higher concentrations (low mM) inhibited SOCE in human platelets [185]. Furthermore, Suzuki et al. observed activation of SOCE by $\mathrm{O}_{2}{ }^{-} \cdot$ but suppression by $\mathrm{H}_{2} \mathrm{O}_{2}$ in mast cells [186].

However, the molecular mechanism(s) underlying the different effects of oxidation and thiol modification on SOCE remained relatively unclear. One of the major reasons for this, as mentioned above, was the unknown molecular identity of the CRAC channels. Recently, using electrophysiology, $\mathrm{Ca}^{2+}$-imaging and site-directed mutagenesis we found that Orai1, but not Orai3 activation is inhibited by preincubation with $\mathrm{H}_{2} \mathrm{O}_{2}$ [187]. Cysteine 195 which is present in Orai1 but absent in Orai3 was identified as a major redox sensor of Orai1, although C126 and C143 also contributed to redox sensitivity. Mutation of all three cysteines in Orai1 render the channels functional but completely insensitive to preincubation with $\mathrm{H}_{2} \mathrm{O}_{2}$, providing evidence that in a heterologous expression system, longer extracellular preincubation with $\mathrm{H}_{2} \mathrm{O}_{2}$ mediates its effects on CRAC solely through oxidation of Orai1. Increased expression of the insensitive Orai3 enables primary effector $T$ cells to reduce their SOCE sensitivity towards extracellular $\mathrm{H}_{2} \mathrm{O}_{2}$ [187]. Acute application of $\mathrm{H}_{2} \mathrm{O}_{2}$ to T cells also induced a rise in internal $\mathrm{Ca}^{2+}$, which is likely independent of Orai1, as siRNA knock-down of Orai1 did not reduce this acute increase in intracellular $\mathrm{Ca}^{2+}$ (unpublished data).

Hawkins et al. [188] studied redox mediated activation of STIM1 and found that oxidative stress leads to gluthationylation of STIM1's cysteine 56, triggering STIM1 oligomerization and punctae

Table 4

Redox regulation of SOCE and CRAC/Orai channels.

\begin{tabular}{|c|c|c|c|c|c|}
\hline SOCE & Cells & Redox modulator & Effect & Target & Ref. \\
\hline Orai1 & $\begin{array}{l}\text { HEK, } \\
\text { CD4 }{ }^{+} \mathrm{T} \text { cells, Jurkat T cells }\end{array}$ & $\mathrm{H}_{2} \mathrm{O}_{2} \mathrm{EC}_{50} \sim 34$ and $40 \mu \mathrm{M}$ & $\begin{array}{l}\downarrow \mathrm{Ca}^{2+} \text { influx } \\
\downarrow \mathrm{Ca}^{2+} \text { current }\end{array}$ & C126, C143, C195 & {$[187]$} \\
\hline STIM1 & $\begin{array}{l}\text { HEK, smooth muscle, neurons, COS7, } \\
\text { DT40 B-cells, MEF, 143B osteosarcoma }\end{array}$ & $\begin{array}{l}\mathrm{H}_{2} \mathrm{O}_{2} \text {, hypoxia, } \\
\text { BSO }\end{array}$ & $\begin{array}{l}\uparrow \mathrm{Ca}^{2+} \text { influx } \\
\uparrow \mathrm{Ca}^{2+} \text { current }\end{array}$ & C56 & {$[188,200-202]$} \\
\hline $\begin{array}{l}\mathrm{IP}_{3} \mathrm{R}, \mathrm{RyR} \\
\text { unidentified } \\
\text { target }\end{array}$ & $\begin{array}{l}\text { RBL, HEK, Jurkat, endothelial cells, } \\
\text { FRTL-5, SH-SY5Y, platelets, smooth } \\
\text { muscle, neutrophils, mast cells, DT40 } \\
\text { B-cells }\end{array}$ & $\begin{array}{l}\mathrm{H}_{2} \mathrm{O}_{2} \text {, hypoxia, thimerosal, } \\
\text { tBHP, vanadate, } \mathrm{O}_{2}^{-} \bullet \\
\text { pervanadate, } \mathrm{HOCl}, \mathrm{NO}, \\
\text { DEANO, GEA3162, SNP, } \\
\mathrm{NO}_{2}^{-}\end{array}$ & $\begin{array}{l}\uparrow \downarrow \mathrm{Ca}^{2+} \text { influx } \\
\uparrow \downarrow \mathrm{Ca}^{2+} \text { current } \\
\text { (see text for } \\
\text { details) }\end{array}$ & $\begin{array}{l}\mathrm{IP}_{3} \mathrm{R} \text { and } \mathrm{RyR} \\
\text { reactive cysteines } \\
\text { and ND }\end{array}$ & $\begin{array}{l}{[171-177,180-186,189} \\
192-195,203-218]\end{array}$ \\
\hline
\end{tabular}

BSO, buthionine sulfoximine; DEANO, 2-(N,N-diethylamino)diazenolate-2-oxide; FRTL-5, fischer rat thyroid low serum 5\%; GEA3162, 1,2,3,4,-oxatriazolium, 5-amino-3-(3,4dichlorophenyl)-chloride; HEK, human embryonic kidney; $\mathrm{IP}_{3} \mathrm{R}, \mathrm{IP}_{3}$ receptor; Jurkat, human leukemic $\mathrm{T}$ cell line; MEF, mouse embryonic fibroblasts; RBL, rat basophilic leukemia; RyR, ryanodine receptor; SH-SY5Y, human neuroblastoma cell line; SNP, sodium nitroprusside; tBHP, tert-butylhydroperoxide. 
formation independently of the ER $\mathrm{Ca}^{2+}$ concentration. Clustered STIM1 proteins are then able to activate Orai channels and induce $\mathrm{Ca}^{2+}$ entry across the PM. STIM1 C47/C56 mutants are constitutively active, although these effects may be due to defective STIM1 EF hand function. Another study by Grupe et al. reports that $\mathrm{H}_{2} \mathrm{O}_{2}$ directly mediates store depletion and thereby activates Orai in a STIM1 dependent manner [189], a finding that we could not reproduce in a heterologous expression system using patch-clamp analyses.

How might these discrepancies be resolved? A number of recent studies investigated the influence of the STIM1:Orai stoichiometry $[190,191]$ on current size, which implies that different STIM:Orai ratios may show differences in their regulatory behavior. It is also of importance to find out under exactly which conditions cysteines in STIM1 and/or STIM2 are oxidized or reduced and what kind of chemical modifications they undergo (e.g. nitrosylation or glutathionylation). In addition, STIM may activate other channels (i.e. TRPCs) leading to an increase in intracellular $\mathrm{Ca}^{2+}$, although their current-voltage relationship should differ from those mediated by Orai (see also Table 4 for a summary of redox regulated activation/inhibition of SOCE).

Another possible explanation of the divergent findings might be that autocrine, intracellularly produced oxidants may favor depletion of the ER $\mathrm{Ca}^{2+}$ stores and STIM oligomerization leading to activation of the CRAC channels, whereas paracrine extracellular production of ROS would first target Orai1 channels (C195) and hence inhibit their activation.

Further precise and detailed studies are needed to shed more light on these complex signaling events. It will also be of importance to clearly define and quantify the types of ROS using the methods outlined above. Application of one kind of ROS in a particular concentration may also change the amount of other ROS, complicating the interpretation of data.

\subsubsection{Hypoxia effects on SOCE and CRAC/ORAI channels}

Oxygen deprivation is a condition of immense clinical importance and a large number of studies investigate the effects of hypoxia on signaling cascades. Here, we will only focus on those aspects of hypoxia that relate to SOCE. Several studies report modulation of SOCE under hypoxic conditions in different cell types (Table 4). While many studies do not investigate the link between hypoxia and the redox state, some indicate that the effects of hypoxia occur via changes in the cellular ROS production. Currently, there is no consensus about the concentrations of ROS induced by hypoxia.

Inhibition of SOCE in hypoxic conditions was shown in several studies [192-195]. Interestingly, two of these studies used chronic hypoxia rat models and not acute induced hypoxia of cells in culture. The molecular mechanism of inhibition was however not identified. On the other hand, Asai et al. showed that SOCE is inhibited by hypoxia through extracellular, but not intracellular acidification [194].

Activation of SOCE by hypoxia was mostly reported upon acute exposure of cultured cells to low amounts of oxygen (2-4\%). Two studies suggested that this activation is governed by up-regulation of TRP channels $[196,197]$ while others localized the ER as the target-site [198-202].

Lu et al. proposed that SOCE activation by hypoxia is via STIM1 while STIM2 played no significant role in this context [200]. Conversely, Berna-Erro et al. [201] reported that STIM2 is essential for the hypoxia induced $\mathrm{Ca}^{2+}$ overload, while manipulations of STIM1 expression had no significant effect. One possible explanation for this discrepancy may be the different cell types used. Lu et al. performed their study in arterial smooth muscle cells while Berna-Erro et al. worked with neurons.

\subsubsection{Reactive nitrogen species effects on SOCE and CRAC/ORAI channels}

The focus of this review is on the role of ROS as modulators of ion channels function. Nevertheless, reactive nitrogen species (RNS) have also been implicated as modulators of ion channel function and their effects on SOCE should not be neglected. Because the targets (reactive cysteines) of ROS and RNS are often identical we will also shortly summarize the present knowledge on the impact of RNS on SOCE. Similar to the effects of ROS and hypoxia, some reports describe inhibition of SOCE by NO and others claim the contrary. In addition, several different mechanisms of action are proposed.

In one of the first reports, Bischof et al. reported that the NO donor sodium nitroprusside (SNP) at $30 \mu \mathrm{M}$ induced inhibition of SOCE while lower $0.5 \mu \mathrm{M}$ SNP had an opposite effect and led to modest enhancement of the $\mathrm{Ca}^{2+}$ entry [203]. Similar findings about the dual, concentration dependent effects of NO and NOdonors on SOCE were also reported in neutrophils and platelets in 2011 [204,205]. Bolotina and co-workers showed in two successive reports that NO inhibits SOCE in human platelets and proposed an accelerated SERCA pumping rate and consequently faster refilling of the ER- $\mathrm{Ca}^{2+}$ stores as the molecular mechanism underlying this event [206,207]. That NO suppresses SOCE function in HEK 293 cells was also shown by Groschner and his colleagues. This effect was induced by application of either NO donor (2- $(\mathrm{N}, \mathrm{N}-$ diethylamino)diazenolate-2-oxide sodium salt, DEANO) or pure NO $(100 \mu \mathrm{M})$. Interestingly, the authors could show that SOCE sensitivity towards NO is abolished upon overexpression of TRPC3 channels [208]. Several additional reports also showed inhibition of SOCE by NO, proposing different mechanisms [209-212].

It has also been reported that NO can have stimulatory effects on SOCE [213]. In 1998 and 1999, the group of Gill reported that NO donors GEA3162, SNP and $\mathrm{NO}_{2}{ }^{-}$activated SOCE independently of guanylate cyclase and suggested thiol oxidation as a modulating mechanism. According to their data, the authors suggest S-nitrosylation either on the proteins within the ER stores or on the PM channels as an underlying mechanism of NO induced SOCE activation $[214,215]$. These findings were confirmed by Watson et al. who proposed that NO induces depletion of ryanodine-sensitive $\mathrm{Ca}^{2+}$ stores and thus leads to activation of SOCE [216].

In 2003, Moneer et al. showed differential NO sensitivity of two independent $\mathrm{Ca}^{2+}$ entry pathways activated by vasopressin in a vascular smooth muscle cell-line. Generation of NO following vasopressin treatment was shown to activate a non-capacitative $\mathrm{Ca}^{2+}$ entry pathway, while inhibiting a capacitative $\mathrm{Ca}^{2+}$ entry via the protein kinase G [217]. Inhibition of SOCE by an NO donor was also reported by Watson at al. [218]. A summary of redox regulation of CRAC/Orai channels is given in Table 4.

\section{Implications and future perspectives}

Regulation of proteins by reversible or irreversible oxidation, glutathionylation or nitrosylation is becoming an increasingly recognized aspect of cellular signaling. The currently used approaches often involve external addition of oxidants. Given the variable and often contradictory results it is questionable to what extent our experimental designs can mimic conditions of ROS and RNS production and diffusion in a biological system. The short-lived nature of these reactive species makes accurate quantification of physiologically produced concentrations a very difficult task.

Many proteins contain a number of potentially reactive cysteines, hindering the interpretation of the effects of ROS in the absence of mutagenesis studies. While mutagenesis of specific residues often is able to pinpoint the molecular targets of ROS (e.g. C157 in TRPV1), this is not always the case, possibly when cysteines 
can be in a reactive and in a non-reactive state (i.e. C558 in TRPC5) or when mutation of a particular cysteine leads to non-functional channels. Future work is also needed to clearly separate effects of potentially increased phosphorylation due to inactivation of phosphatases. The development of faster and more accurate in vivo ROS indicators will increase elucidation of physiological ROS production and its effects. Considering the important roles of $\mathrm{Ca}^{2+}$ conducting ion channels such as CaV, TRP and CRAC/Orai channels for cellular functions, detailed molecular analyses of their redox regulation on a molecular and physiological level will help to understand the interplay between $\mathrm{Ca}^{2+}$ and ROS signaling. The many inconsistent findings regarding ROS modulation of $\mathrm{Ca}^{2+}$ channels highlight the necessity to better control and quantify ROS, to identify molecular targets and to consider complex interactions between them.

\section{Acknowledgement}

We are very grateful to Dr. V. Mirčeski and members of the laboratory for critically reading the manuscript. This work is supported by the Alexander von Humboldt Foundation via the joint German-Macedonian project from the Research Group Linkage Programme 3.4-Fokoop-DEU/1128670 (to IB, RK, RG and MH) and by the Deutsche Forschungsgemeinschaft: Individual grants KA $1242 / 1$ and $1242 / 2$ to RK, SFB 530, project A3, SFB 894, project A1 and GK 845 to MH and SFB 894, project A2 and GK 1326 to BAN.

\section{References}

[1] W. Droge, Free radicals in the physiological control of cell function, Physiol. Rev. 82 (2002) 47-95.

[2] B. Halliwell, J. Gutteridge, Free Radicals in Biology and Medicine, Oxford University Press, 2007

[3] B.M. Babior, NADPH oxidase, Curr. Opin. Immunol. 16 (2004) 42-47.

[4] K. Bedard, K.H. Krause, The NOX family of ROS-generating NADPH oxidases: physiology and pathophysiology, Physiol. Rev. 87 (2007) 245-313.

[5] J.D. Lambeth, NOX enzymes and the biology of reactive oxygen, Nat. Rev. Immunol. 4 (2004) 181-189.

[6] M. Geiszt, T.L. Leto, The Nox family of NAD(P)H oxidases: Host defense and beyond, J. Biol. Chem. 279 (2004) 51715-51718.

[7] Y. Nisimoto, H.M. Jackson, H. Ogawa, T. Kawahara, J. David Lambeth, Constitutive NADPH-dependent electron transferase activity of the Nox4 dehydrogenase domain, Biochemistry 49 (2010) 2433-2442.

[8] Á. Donkó, Z. Péterfi, A. Sum, T. Leto, M. Geiszt, Dual oxidases, Philos. Trans. R. Soc. B: Biol. Sci. 360 (2005) 2301-2308.

[9] B. Bánfi, G. Molnár, A. Maturana, K. Steger, B. Hegedûs, N. Demaurex, K.H. Krause, $\mathrm{A} \mathrm{Ca}^{2+}$-activated NADPH oxidase in testis, spleen, and lymph nodes, J. Biol. Chem. 276 (2001) 37594-37601.

[10] S. Miwa, K.B. Beckman, F.L. Muller, The basics of oxidative biochemistry, in: Aging Medicine: Oxidative Stress in Aging: From Model Systems to Human Diseases, Humana Press, 2010.

[11] E. Cadenas, K.J. Davies, Mitochondrial free radical generation, oxidative stress, and aging, Free Radic. Biol. Med. 29 (2000) 222-230.

[12] P.S. Brookes, Y. Yoon, J.L. Robotham, M.W. Anders, S.S. Sheu, Calcium ATP, and ROS: a mitochondrial love-hate triangle, Am. J. Physiol. Cell Physiol. 287 (2004) C817-C833.

[13] J. Satrústegui, B. Pardo, A. Del Arco, Mitochondrial transporters as novel targets for intracellular calcium signaling, Physiol. Rev. 87 (2007) 29-67.

[14] I. Bogeski, M. Bozem, L. Sternfeld, H.W. Hofer, I. Schulz, Inhibition of protein tyrosine phosphatase $1 \mathrm{~B}$ by reactive oxygen species leads to maintenance of $\mathrm{Ca}^{2+}$ influx following store depletion in HEK 293 cells, Cell Calcium 40 (2006) $1-10$.

[15] C. Walsh, S. Barrow, S. Voronina, M. Chvanov, O.H. Petersen, A. Tepikin, Modulation of calcium signalling by mitochondria, Biochim. Biophys. Acta - Bioenerg. 1787 (2009) 1374-1382.

[16] T. Chakraborti, S. Das, M. Mondal, S. Roychoudhury, S. Chakraborti, Oxidant, mitochondria and calcium: an overview, Cell. Signal. 11 (1999) 77-85.

[17] C. Chinopoulos, V. Adam-Vizi, Calcium, mitochondria and oxidative stress in neuronal pathology: novel aspects of an enduring theme, FEBS J. 273 (2006) 433-450.

[18] A.J. Kowaltowski, N.C. de Souza-Pinto, R.F. Castilho, A.E. Vercesi, Mitochondria and reactive oxygen species, Free Radic. Biol. Med. 47 (2009) 333-343.

[19] J.F. Turrens, Mitochondrial formation of reactive oxygen species, J. Physiol. 552 (2003) 335-344

[20] M.P. Murphy, How mitochondria produce reactive oxygen species, Biochem. J. 417 (2009) 1-13.

[21] H. Nohl, L. Gille, K. Staniek, Intracellular generation of reactive oxygen species by mitochondria, Biochem. Pharmacol. 69 (2005) 719-723.
[22] M. Ott, V. Gogvadze, S. Orrenius, B. Zhivotovsky, Mitochondria, oxidative stress and cell death, Apoptosis 12 (2007) 913-922.

[23] R.P. Brandes, M. Janiszewski, Direct detection of reactive oxygen species ex vivo, Kidney Int. 67 (2005) 1662-1664.

[24] E.A. Veal, A.M. Day, B.A. Morgan, Hydrogen peroxide sensing and signaling, Mol. Cell 26 (2007) 1-14

[25] M.M. Tarpey, D.A. Wink, M.B. Grisham, Methods for detection of reactive metabolites of oxygen and nitrogen: in vitro and in vivo considerations, Am. J. Physiol. Regul. Integr. Compar. Physiol. 286 (2004) R431-R444.

[26] E.W. Miller, O. Tulyanthan, E.Y. Isacoff, C.J. Chang, Molecular imaging of hydrogen peroxide produced for cell signaling, Nat. Chem. Biol. 3 (2007) 263-267.

[27] M.M. Tarpey, I. Fridovich, Methods of detection of vascular reactive species: nitric oxide, superoxide, hydrogen peroxide, and peroxynitrite, Circ. Res. 89 (2001) 224-236

[28] P. Wardman, Fluorescent and luminescent probes for measurement of oxidative and nitrosative species in cells and tissues: progress, pitfalls, and prospects, Free Radic. Biol. Med. 43 (2007) 995-1022.

[29] A. Gomes, E. Fernandes, J.L.F.C. Lima, Fluorescence probes used for detection of reactive oxygen species, J. Biochem. Biophys. Methods 65 (2005) 45-80.

[30] A.J. Meyer, T.P. Dick, Fluorescent protein-based redox probes, Antioxid. Redox Signal. 13 (2010) 621-650.

[31] E.W Miller, A.E. Albers, A. Pralle, E.Y. Isacoff, C.J. Chang, Boronate-based fluorescent probes for imaging cellular hydrogen peroxide, J. Am. Chem. Soc. 127 (2005) 16652-16659.

[32] E.W. Miller, C.J. Chang, Fluorescent probes for nitric oxide and hydrogen peroxide in cell signaling, Curr. Opin. Chem. Biol. 11 (2007) 620-625.

[33] H. Maeda, Y. Fukuyasu, S. Yoshida, M. Fukuda, K. Saeki, H. Matsuno, Y. Yamauchi, K. Yoshida, K. Hirata, K. Miyamoto, Fluorescent probes for hydrogen peroxide based on a non-oxidative mechanism, Angew. Chem. - Int. Ed. 43 (2004) 2389-2391.

[34] H. Maeda, K. Yamamoto, I. Kohno, L. Hafsi, N. Itoh, S. Nakagawa, N. Kanagawa, K. Suzuki, T. Uno, Design of a practical fluorescent probe for superoxide based on protection-deprotection chemistry of fluoresceins with benzenesulfonyl protecting groups, Chem. Eur. J. 13 (2007) 1946-1954.

[35] H. Maeda, K. Yamamoto, Y. Nomura, I. Kohno, L. Hafsi, N. Ueda, S. Yoshida, M. Fukuda, Y. Fukuyasu, Y. Yamauchi, N. Itoh, A design of fluorescent probes for superoxide based on a nonredox mechanism, J. Am. Chem. Soc. 127 (2005) 68-69.

[36] N. Soh, O. Sakawaki, K. Makihara, Y. Odo, T. Fukaminato, T. Kawai, M. Irie, T. Imato, Design and development of a fluorescent probe for monitoring hydrogen peroxide using photoinduced electron transfer, Bioorg. Med. Chem. 13 (2005) 1131-1139.

[37] O.S Wolfbeis, A. Dürkop, M. Wu, Z. Lin, A europium-ion-based luminescent sensing probe for hydrogen peroxide, Angew. Chem. Int. Ed. 41 (2002) 4495-4498.

[38] K. Xu, B. Tang, H. Huang, G. Yang, Z. Chen, P. Li, L. An, Strong red fluorescent probes suitable for detecting hydrogen peroxide generated by mice peritoneal macrophages, Chem. Commun. 48 (2005) 5974-5976.

[39] D. Yang, H.L. Wang, Z.N. Sun, N.W. Chung, J.G. Shen, A highly selective fluorescent probe for the detection and imaging of peroxynitrite in living cells, J. Am. Chem. Soc. 128 (2006) 6004-6005.

[40] M.C.Y. Chang, A. Pralle, E.Y. Isacoff, C.J. Chang, A selective, cell-permeable optical probe for hydrogen peroxide in living cells, J. Am. Chem. Soc. 126 (2004) 15392-15393.

[41] C. Rota, C.F. Chignell, R.P. Mason, Evidence for free radical formation during the oxidation of $2^{\prime}-7^{\prime}$-dichlorofluorescin to the fluorescent dye $2^{\prime}$ $7^{\prime}$-dichlorofluorescein by horseradish peroxidase: possible implications for oxidative stress measurements, Free Radic. Biol. Med. 27 (1999) 873-881.

[42] M. Gutscher, A.L. Pauleau, L. Marty, T. Brach, G.H. Wabnitz, Y. Samstag, A.J. Meyer, T.P. Dick, Real-time imaging of the intracellular glutathione redox potential, Nat. Methods 5 (2008) 553-559.

[43] H. Østergaard, A. Henriksen, F.G. Hansen, J.R. Winther, Shedding light on disulfide bond formation: engineering a redox switch in green fluorescent protein, EMBO J. 20 (2001) 5853-5862.

[44] G. Maulucci, V. Labate, M. Mele, E. Panieri, G. Arcovito, T. Galeotti, H. Østergaard, J.R. Winther, M. De Spirito, G. Pani, High-resolution imaging of redox signaling in live cells through an oxidation-sensitive yellow fluorescent protein, Sci. Signal. 1 (2008) pl3.

[45] C.T. Dooley, T.M. Dore, G.T. Hanson, W.C. Jackson, S.J. Remington, R.Y. Tsien, Imaging dynamic redox changes in mammalian cells with green fluorescent protein indicators, J. Biol. Chem. 279 (2004) 22284-22293.

[46] G.T. Hanson, R. Aggeler, D. Oglesbee, M. Cannon, R.A. Capaldi, R.Y. Tsien, S.J. Remington, Investigating mitochondrial redox potential with redox-sensitive green fluorescent protein indicators, J. Biol. Chem. 279 (2004) 13044-13053.

[47] V.V. Belousov, A.F. Fradkov, K.A. Lukyanov, D.B. Staroverov, K.S. Shakhbazov, A.V. Terskikh, S. Lukyanov, Genetically encoded fluorescent indicator for intracellular hydrogen peroxide, Nat. Methods 3 (2006) 281-286.

[48] V.L. Kolossov, B.Q. Spring, A. Sokolowski, J.E. Conour, R.M. Clegg, P.J.A. Kenis, H.R. Gaskins, Engineering redox-sensitive linkers for genetically encoded FRET-based biosensors, Exp. Biol. Med. 233 (2008) 238-248.

[49] S. Borgmann, Electrochemical quantification of reactive oxygen and nitrogen: challenges and opportunities, Anal. Bioanal. Chem. 394 (2009) 95-105.

[50] V. Brovkovych, E. Stolarczyk, J. Oman, P. Tomboulian, T. Malinski, Direct electrochemical measurement of nitric oxide in vascular endothelium, J. Pharm. Biomed. Anal. 19 (1999) 135-143. 
[51] I. Bogeski, V. Mirceski, M. Hoth, Probing the redox activity of T-lymphocytes deposited at electrode surfaces with voltammetric methods, Clin. Chem. Lab. Med. 46 (2008) 197-203.

[52] R.M. Wightman, Probing cellular chemistry in biological systems with microelectrodes, Science 311 (2006) 1570-1574.

[53] F. Bedioui, N. Villeneuve, Electrochemical nitric oxide sensors for biological samples - principle, selected examples and applications, Electroanalysis 15 (2003) 5-18.

[54] A. Schulte, W. Schuhmann, Single-cell microelectrochemistry, Angew. Chem. Int. Ed. 46 (2007) 8760-8777.

[55] C. Amatore, S. Arbault, C. Bouton, K. Coffi, J.C. Drapier, H. Ghandour, Y. Tong, Monitoring in real time with a microelectrode the release of reactive oxygen and nitrogen species by a single macrophage stimulated by its membrane mechanical depolarization, ChemBioChem 7 (2006) 653-661.

[56] C. Amatore, S. Arbault, M. Guille, F. Lemaître, Electrochemical monitoring of single cell secretion: vesicular exocytosis and oxidative stress, Chem. Rev. 108 (2008) 2585-2621.

[57] Y. Lee, J. Yang, S.M. Rudich, R.J. Schreiner, M.E. Meyerhoff, Improved planar amperometric nitric oxide sensor based on platinized platinum anode. 2 . direct real-time measurement of NO generated from porcine kidney slices in the presence of L-arginine, L-arginine polymers, and protamine, Anal. Chem. 76 (2004) 545-551.

[58] S. Isik, M. Etienne, J. Oni, A. Blöchi, S. Reiter, W. Schuhmann, Dual microelectrodes for distance control and detection of nitric oxide from endothelia cells by means of scanning electrochemical microscope, Anal. Chem. 76(2004) 6389-6394.

[59] S. Isik, W. Schuhmann, Detection of nitric oxide release from single cells by using constant-distance-mode scanning electrochemical microscopy, Angew. Chem. Int. Ed. 45 (2006) 7451-7454

[60] M. Kohno, Applications of electron spin resonance spectrometry for reactive oxygen species and reactive nitrogen species research, J. Clin. Biochem. Nutr. $47(2010) 1-11$.

[61] M.J. Davies, Recent developments in EPR spin-trapping, Special. Period. Reports Electron Paramagn. Resonance 18 (2002) 47-73.

[62] O. Ouari, M. Hardy, H. Karoui, P. Tordo, Recent developments and applications of the coupled EPR/Spin trapping technique (EPR/ST), Special. Period. Reports, Electron Paramagn. Resonance 22 (2011) 1-40.

[63] S.I. Dikalov, W. Li, P. Mehranpour, S.S. Wang, A.M. Zafari, Production of extracellular superoxide by human lymphoblast cell lines: comparison of electron spin resonance techniques and cytochrome $C$ reduction assay, Biochem. Pharmacol. 73 (2007) 972-980.

[64] M.J. Berridge, P. Lipp, M.D. Bootman, The versatility and universality of calcium signalling, Nat. Rev. Mol. Cell. Biol. 1 (2000) 11-21.

[65] D.E. Clapham, Calcium signaling, Cell 131 (2007) 1047-1058.

[66] A.P. Thomas, G.S.T.J. Bird, G. Hajnóczky, L.D. Robb-Gaspers, J.W. Putney Jr., Spatial and temporal aspects of cellular calcium signaling, FASEB J. 10 (1996) 1505-1517.

[67] E.M. Brown, R.J. Macleod, Extracellular calcium sensing and extracellular calcium signaling, Physiol. Rev. 81 (2001) 239-297.

[68] A.M. Hofer, E.M. Brown, Extracellular calcium sensing and signalling, Nat. Rev. Mol. Cell Biol. 4 (2003) 530-538.

[69] W.A. Catterall, Structure and regulation of voltage-gated $\mathrm{Ca}^{2+}$ channels, Ann Rev. Cell. Dev. Biol. 16 (2000) 521-555.

[70] D.E. Clapham, L.W. Runnels, C. Strübing, The TRP ion channel family, Nat. Rev. Neurosci. 2 (2001) 387-396.

[71] B. Minke, B. Cook, TRP channel proteins and signal transduction, Physiol. Rev. 82 (2002) 429-472.

[72] Montell, C., 2005. The TRP superfamily of cation channels. Sci. STKE [electronic resource]: signal transduction knowledge environment, 272 , re3.

[73] S.F. Pedersen, G. Owsianik, B. Nilius, TRP channels: an overview, Cell Calcium 38 (2005) 233-252.

[74] A.B. Parekh, J.W. Putney Jr., Store-operated calcium channels, Physiol. Rev. 85 (2005) 757-810.

[75] P. Koulen, Y. Cai, L. Geng, Y. Maeda, S. Nishimura, R. Witzgall, B.E. Ehrlich, S Somlo, Polycystin-2 is an intracellular calcium release channel, Nat. Cell Biol. 4 (2002) 191-197.

[76] S. Patel, R. Docampo, In with the TRP channels: intracellular functions for TRPM1 and TRPM2, Sci. Signal. 2 (2009) pe69.

[77] S. Orrenius, B. Zhivotovsky, P. Nicotera, Regulation of cell death: the calciumapoptosis link, Nat. Rev. Mol. Cell Biol. 4 (2003) 552-565.

[78] J.K. Foskett, C. White, K.H. Cheung, D.O.D. Mak, Inositol trisphosphate receptor $\mathrm{Ca}^{2+}$ release channels, Physiol. Rev. 87 (2007) 593-658.

[79] M.J. Berridge, Inositol trisphosphate and calcium signalling, Nature 361 (1993) 315-325.

[80] M.J. Berridge, The endoplasmic reticulum: a multifunctional signaling organelle, Cell Calcium 32 (2002) 235-249.

[81] A. Guerrero-Hernandez, A. Dagnino-Acosta, A. Verkhratsky, An intelligent sarco-endoplasmic reticulum $\mathrm{Ca}^{2+}$ store: release and leak channels have differential access to a concealed $\mathrm{Ca}^{2+}$ pool, Cell Calcium 48 (2010) 143-149.

[82] F. Van Coppenolle, F. Vanden Abeele, C. Slomianny, M. Flourakis, J. Hesketh, E. Dewailly, N. Prevarskaya, Ribosome-translocon complex mediates calcium leakage from endoplasmic reticulum stores, J. Sci. 117 (2004) 4135-4142.

[83] R.B. Lomax, C. Camello, F. Van Coppenolle, O.H. Petersen, A.V. Tepikin, Basa and physiological $\mathrm{Ca}^{2+}$ leak from the endoplasmic reticulum of pancreatic acinar cells. Second messenger-activated channels and translocons, J. Biol. Chem. 277 (2002) 26479-26485.
[84] H. Tu, O. Nelson, A. Bezprozvanny, Z. Wang, S.F. Lee, Y.H. Hao, L. Serneels, B. De Strooper, G. Yu, I. Bezprozvanny, Presenilins form ER Ca ${ }^{2+}$ leak channels, a function disrupted by familial Alzheimer's disease-linked mutations, Cell 126 (2006) 981-993.

[85] C. Camello, R. Lomax, O.H. Petersen, A.V. Tepikin, Calcium leak from intracellular stores - the enigma of calcium signalling, Cell Calcium 32 (2002) 355-361.

[86] F. Erdmann, N. Schäuble, S. Lang, M. Jung, A. Honigmann, M. Ahmad, J. Dudek, J. Benedix, A. Harsman, A. Kopp, V. Helms, A. Cavalié, R. Wagner, R. Zimmermann, Interaction of calmodulin with Sec61 $\alpha$ limits $\mathrm{Ca}^{2+}$ leakage from the endoplasmic reticulum, EMBO J. 30 (2011) 17-31.

[87] M. Flourakis, F. Van Coppenolle, V. Lehen'kyi, B. Beck, R. Skryma, N. Prevarskaya, Passive calcium leak via translocon is a first step for iPLA2-pathway regulated store operated channels activation, FASEB J. 20 (2006) 12151217.

[88] R. Giunti, A. Gamberucci, R. Fulceri, G. Banhegyi, A. Benedetti, Both translocon and a cation channel are involved in the passive $\mathrm{Ca}^{2+}$ leak from the endoplasmic reticulum: a mechanistic study on rat liver microsomes, Arch. Biochem. Biophys. 462 (2007) 115-121.

[89] T.E. Gunter, D.R. Pfeiffer, Mechanisms by which mitochondria transport calcium, Am. J. Physiol. Cell Physiol. 258 (1990) C755-C786.

[90] R. Rizzuto, T. Pozzan, Microdomains of intracellular $\mathrm{Ca}^{2+}:$ molecular determinants and functional consequences, Physiol. Rev. 86 (2006) 369-408.

[91] M.R. Duchen, Mitochondria and $\mathrm{Ca}^{2+}$ in cell physiology and pathophysiology, Cell Calcium 28 (2000) 339-348.

[92] W. Tan, M. Colombini, VDAC closure increases calcium ion flux, Biochim. Biophys. Acta (BBA) Biomemb. 1768 (2007) 2510-2515.

[93] E. Rapizzi, P. Pinton, G. Szabadkai, M.R. Wieckowski, G. Vandecasteele, G. Baird, R.A. Tuft, K.E. Fogarty, R. Rizzuto, Recombinant expression of the voltage-dependent anion channel enhances the transfer of $\mathrm{Ca}^{2+}$ microdomains to mitochondria, J. Cell Biol. 159 (2002) 613-624.

[94] G. Bathori, G. Csordas, C. Garcia-Perez, E. Davies, G. Hajnoczky, Ca ${ }^{2+}$ dependent control of the permeability properties of the mitochondrial outer membrane and voltage-dependent anion-selective channel (VDAC), J. Biol. Chem. 281 (2006) 17347-17358.

[95] J. Santo-Domingo, N. Demaurex, Calcium uptake mechanisms of mitochondria, Biochim. Biophys. Acta Bioenerg. 1797 (2010) 907-912.

[96] D. De Stefani, A. Raffaello, E. Teardo, I. Szabo, R. Rizzuto, A forty-kilodalton protein of the inner membrane is the mitochondrial calcium uniporter, Nature 476 (2011) 336-340.

[97] J.M. Baughman, F. Perocchi, H.S. Girgis, M. Plovanich, C.A. Belcher-Timme, Y. Sancak, X.R. Bao, L. Strittmatter, O. Goldberger, R.L. Bogorad, V. Koteliansky, V.K. Mootha, Integrative genomics identifies MCU as an essential component of the mitochondrial calcium uniporter, Nature 476 (2011) 341-345.

[98] D. Jiang, L. Zhao, D.E. Clapham, Genome-wide RNAi screen identifies Letm1 as a mitochondrial $\mathrm{Ca}^{2+} / \mathrm{H}^{+}$antiporter, Science 326 (2009) 144-147.

[99] I. Bogeski, R. Gulaboski, R. Kappl, V. Mirceski, M. Stefova, J. Petreska, M. Hoth Calcium binding and transport by coenzyme q, J. Am. Chem. Soc. 133 (2011) 9293-9303.

[100] V. Mirceski, R. Gulaboski, I. Bogeski, M. Hoth, Redox chemistry of Catransporter 2-palmitoylhydroquinone in an artificial thin organic film membrane, J. Phys. Chem. C 111 (2007) 6068-6076.

[101] F. Ichas, L.S. Jouaville, J.P. Mazat, Mitochondria are excitable organelles capable of generating and conveying electrical and calcium signals, Cell 89 (1997) 1145-1153.

[102] P.J. Pomposiello, B. Demple, Redox-operated genetic switches: the SoxR and OxyR transcription factors, Trends Biotechnol. 19 (2001) 109-114.

[103] M. Zheng, F. Åslund, G. Storz, Activation of the OxyR transcription factor by reversible disulfide bond formation, Science 279 (1998) 1718-1721.

[104] K.K. Griendling, D. Sorescu, B. Lassègue, M. Ushio-Fukai, Modulation of protein kinase activity and gene expression by reactive oxygen species and their role in vascular physiology and pathophysiology, Arteriosc. Thromb. Vasc. Biol. 20 (2000) 2175-2183.

[105] N.K. Tonks, Redox redux: revisiting PTPs and the control of cell signaling, Cell 121 (2005) 667-670.

[106] R.L. van Montfort, M. Congreve, D. Tisi, R. Carr, H. Jhoti, Oxidation state of the active-site cysteine in protein tyrosine phosphatase 1B, Nature 423 (2003) 773-777.

[107] C. Hidalgo, P. Donoso, Crosstalk between calcium and redox signaling: from molecular mechanisms to health implications, Antioxid. Redox Signal. 10 (2008) 1275-1312.

[108] A.V.Zima, L.A. Blatter, Redox regulation of cardiac calcium channels and transporters, Cardiovasc. Res. 71 (2006) 310-321.

[109] L.C. Hool, B. Corry, Redox control of calcium channels: from mechanisms to therapeutic opportunities, Antioxid. Redox Signal. 9 (2007) 409-435.

[110] K. Venkatachalam, C. Montell, TRP channels, Ann. Rev. Biochem. 76 (2007) 387-417.

[111] L.J. Wu, T.B. Sweet, D.E. Clapham, International union of basic and clinical pharmacology. LXXVI. Current progress in the mammalian TRP ion channel family, Pharmacol. Rev. 62 (2010) 381-404.

[112] M. Bandell, G.M. Story, S.W. Hwang, V. Viswanath, S.R. Eid, M.J. Petrus, T.J. Earley, A. Patapoutian, Noxious cold ion channel TRPA1 is activated by pungent compounds and bradykinin, Neuron 41 (2004) 849-857.

[113] D.M. Bautista, S.E. Jordt, T. Nikai, P.R. Tsuruda, A.J. Read, J. Poblete, E.N Yamoah, A.I. Basbaum, D. Julius, TRPA1 mediates the inflammatory actions of environmental irritants and proalgesic agents, Cell 124 (2006) 1269-1282. 
[114] D.M. Bautista, P. Movahed, A. Hinman, H.E. Axelsson, O. Sterner, E.D. Hogestatt, D. Julius, S.E. Jordt, P.M. Zygmunt, Pungent products from garlic activate the sensory ion channel TRPA1, Proc. Natl. Acad. Sci. U. S. A. 102 (2005) 12248-12252.

[115] S.E. Jordt, D.M. Bautista, H.H. Chuang, D.D. McKemy, P.M. Zygmunt, E.D. Hogestatt, I.D. Meng, D. Julius, Mustard oils and cannabinoids excite sensory nerve fibres through the TRP channel ANKTM1, Nature 427 (2004) 260-265.

[116] L.J. Macpherson, B.H. Geierstanger, V. Viswanath, M. Bandell, S.R. Eid, S. Hwang, A. Patapoutian, The pungency of garlic: activation of TRPA1 and TRPV1 in response to allicin, Curr. Biol. 15 (2005) 929-934.

[117] L.J. Macpherson, B. Xiao, K.Y. Kwan, M.J. Petrus, A.E. Dubin, S. Hwang, B. Cravatt, D.P. Corey, A. Patapoutian, An ion channel essential for sensing chemical damage, J. Neurosci. 27 (2007) 11412-11415.

[118] D.A. Andersson, C. Gentry, S. Moss, S. Bevan, Transient receptor potential A1 is a sensory receptor for multiple products of oxidative stress, J. Neurosci. 28 (2008) 2485-2494

[119] T. Streng, H.E. Axelsson, P. Hedlund, D.A. Andersson, S.E. Jordt, S. Bevan, K.E. Andersson, E.D. Hogestatt, P.M. Zygmunt, Distribution and function of the hydrogen sulfide-sensitive TRPA1 ion channel in rat urinary bladder, Eur. Urol. 53 (2008) 391-399.

[120] A. Hinman, H.H. Chuang, D.M. Bautista, D. Julius, TRP channel activation by reversible covalent modification, Proc. Natl. Acad. Sci. U. S. A. 103 (2006) $19564-19568$

[121] L.J. Macpherson, A.E. Dubin, M.J. Evans, F. Marr, P.G. Schultz, B.F. Cravatt, A. Patapoutian, Noxious compounds activate TRPA1 ion channels through covalent modification of cysteines, Nature 445 (2007) 541-545.

[122] K. Kang, S.R. Pulver, V.C. Panzano, E.C. Chang, L.C. Griffith, D.L. Theobald, P.A Garrity, Analysis of Drosophila TRPA1 reveals an ancient origin for human chemical nociception, Nature 464 (2010) 597-600.

[123] H. Salazar, I. Llorente, A. Jara-Oseguera, R. Garcia-Villegas, M. Munari, S.E. Gordon, L.D. Islas, T. Rosenbaum, A single N-terminal cysteine in TRPV1 determines activation by pungent compounds from onion and garlic, Nat. Neurosci. 11 (2008) 255-261.

[124] N. Takahashi, D. Kozai, R. Kobayashi, M. Ebert, Y. Mori, Roles of TRPM2 in oxidative stress, Cell Calcium (2011), doi:10.1016/j.ceca.2011.04.006.

[125] J. Eisfeld, A. Lückhoff, TRPM2, Handb Exp. Pharmacol. 179 (2007) 237-252.

[126] C. Harteneck, Function and pharmacology of TRPM cation channels, NaunynSchmiedeberg's Arch. Pharmacol. 371 (2005) 307-314.

[127] A.L. Perraud, C. Schmitz, A.M. Scharenberg, TRPM2 Ca2+ permeable cation channels: from gene to biological function, Cell Calcium 33 (2003) 519-531.

[128] Y. Hara, M. Wakamori, M. Ishii, E. Maeno, M. Nishida, T. Yoshida, H. Yamada, S. Shimizu, E. Mori, J. Kudoh, N. Shimizu, H. Kurose, Y. Okada, K. Imoto, Y. Mori, LTRPC2 $\mathrm{Ca}^{2+}$-permeable channel activated by changes in redox status confers susceptibility to cell death, Mol. Cell. 9 (2002) 163-173.

[129] A.L. Perraud, C.L. Takanishi, B. Shen, S. Kang, M.K. Smith, C. Schmitz, H.M Knowles, D. Ferraris, W. Li, J. Zhang, B.L. Stoddard, A.M. Scharenberg, Accumulation of free ADP-ribose from mitochondria mediates oxidative stress-induced gating of TRPM2 cation channels, J. Biol. Chem. 280 (2005) 6138-6148.

[130] B. Buelow, Y. Song, A.M. Scharenberg, The Poly(ADP-ribose) polymerase PARP-1 is required for oxidative stress-induced TRPM2 activation in lymphocytes, J. Biol. Chem. 283 (2008) 24571-24583.

[131] S. Yamamoto, S. Shimizu, S. Kiyonaka, N. Takahashi, T. Wajima, Y. Hara, T. Negoro, T. Hiroi, Y. Kiuchi, T. Okada, S. Kaneko, I. Lange, A. Fleig, R. Penner, M. Nishi, H. Takeshima, Y. Mori, TRPM2-mediated $\mathrm{Ca}^{2+}$ influx induces chemokine production in monocytes that aggravates inflammatory neutrophil infiltration, Nat. Med. 14 (2008) 738-747.

[132] S. Kaneko, S. Kawakami, Y. Hara, M. Wakamori, E. Itoh, T. Minami, Y. Takada, T. Kume, H. Katsuki, Y. Mori, A. Akaike, A critical role of TRPM2 in neuronal cell death by hydrogen peroxide, J. Pharmacol. Sci. 101 (2006) 66-76.

[133] M.E. Olah, M.F. Jackson, H. Li, Y. Perez, H.S. Sun, S. Kiyonaka, Y. Mori, M. Tymianski, J.F. Macdonald, $\mathrm{Ca}^{2+}$-dependent induction of TRPM2 currents in hippocampal neurons, J. Physiol. 587 (2009) 965-979.

[134] F. Simon, E. Leiva-Salcedo, R. Armisén, A. Riveros, O. Cerda, D. Varela, A.L. Eguiguren, P. Olivero, A. Stutzin, Hydrogen peroxide removes TRPM4 current desensitization conferring increased vulnerability to necrotic cell death, J. Biol. Chem. 285 (2010) 37150-37158.

[135] P. Launay, A. Fleig, A.L. Perraud, A.M. Scharenberg, R. Penner, J.P. Kinet, TRPM4 is a $\mathrm{Ca}^{2+}$-activated nonselective cation channel mediating cell membrane depolarization, Cell 109 (2002) 397-407.

[136] D. Prawitt, M.K. Monteilh-Zoller, L. Brixel, C. Spangenberg, B. Zabel, A. Fleig, R. Penner, TRPM5 is a transient $\mathrm{Ca}^{2+}$-activated cation channel responding to rapid changes in [Ca2+]i, Proc. Natl. Acad. Sci. U. S. A. 100 (2003) 1516615171.

[137] M. Matsushita, J.A. Kozak, Y. Shimizu, D.T. McLachlin, H. Yamaguchi, F.-Y. Wei, K. Tomizawa, H. Matsui, B.T. Chait, M.D. Cahalan, A.C. Nairn, Channel function is dissociated from the intrinsic kinase activity and autophosphorylation of TRPM7/ChaK1, J. Biol. Chem. 280 (2005) 20793-20803.

[138] M.J.S. Nadler, M.C. Hermosura, K. Inabe, A.-L. Perraud, O. Zhu, A.J. Stokes, T. Kurosaki, J.-P. Kinet, R. Penner, A.M. Scharenberg, A. Fleig, LTRPC7 is a $\mathrm{Mg}[$ middot]ATP-regulated divalent cation channel required for cell viability, Nature 411 (2001) 590-595.

[139] T. Voets, B. Nilius, S. Hoefs, A.W.C.M. van der Kemp, G. Droogmans, R.J.M. Bindels, J.G.J. Hoenderop, TRPM6 forms the $\mathrm{Mg}^{2+}$ influx channel involved in intestinal and renal $\mathrm{Mg}^{2+}$ absorption, J. Biol. Chem. 279 (2004) 19-25.
[140] K.P. Schlingmann, S. Weber, M. Peters, L. Niemann Nejsum, H. Vitzthum, K. Klingel, M. Kratz, E. Haddad, E. Ristoff, D. Dinour, M. Syrrou, S. Nielsen, M. Sassen, S. Waldegger, H.W. Seyberth, M. Konrad, Hypomagnesemia with secondary hypocalcemia is caused by mutations in TRPM6, a new member of the TRPM gene family, Nat. Genet. 31 (2002) 166-170.

[141] R.Y. Walder, D. Landau, P. Meyer, H. Shalev, M. Tsolia, Z. Borochowitz, M.B. Boettger, G.E. Beck, R.K. Englehardt, R. Carmi, V.C. Sheffield, Mutation of TRPM6 causes familial hypomagnesemia with secondary hypocalcemia, Nat. Genet. 31 (2002) 171-174.

[142] M.A. Ciorba, S.H. Heinemann, H. Weissbach, N. Brot, T. Hoshi, Modulation of potassium channel function by methionine oxidation and reduction, Proc. Natl. Acad. Sci. U. S. A. 94 (1997) 9932-9937.

[143] M. Aarts, K. Iihara, W.L. Wei, Z.G. Xiong, M. Arundine, W. Cerwinski, J.F. MacDonald, M. Tymianski, A key role for TRPM7 channels in anoxic neuronal death, Cell 115 (2003) 863-877.

[144] B.A. Miller, W. Zhang, TRP channels as mediators of oxidative stress, Adv. Exp. Med. Biol. 704 (2011) 531-544.

[145] S. Yamamoto, N. Takahashi, Y. Mori, Chemical physiology of oxidative stressactivated TRPM2 and TRPC5 channels, Prog. Biophys. Mol. Biol. 103 (2010) 18-27.

[146] M. Trebak, R. Ginnan, H.A. Singer, D. Jourd'Heuil, Interplay between calcium and reactive oxygen/nitrogen species: an essential paradigm for vascular smooth muscle signaling, Antioxid. Redox Signal. 12 (2010) 657-674.

[147] D.L Cioffi, redox regulation of endothelial canonical transient receptor potential channels, Antioxid. Redox Signal. 15 (2011) 1567-1582.

[148] M. Balzer, B. Lintschinger, K. Groschner, Evidence for a role of Trp proteins in the oxidative stress-induced membrane conductances of porcine aortic endothelial cells, Cardiovasc. Res. 42 (1999) 543-549.

[149] K. Groschner, C. Rosker, M. Lukas, Role of TRP channels in oxidative stress, Novartis Found Symp. 258, 222-30 (2004) 222-230 (discussion 231-5, 263-6).

[150] T. Yoshida, R. Inoue, T. Morii, N. Takahashi, S. Yamamoto, Y. Hara, M. Tominaga, S. Shimizu, Y. Sato, Y. Mori, Nitric oxide activates TRP channels by cysteine S-nitrosylation, Nat. Chem. Biol. 2 (2006) 596-607.

[151] S.Z. Xu, P. Sukumar, F. Zeng, J. Li, A. Jairaman, A. English, J. Naylor, C. Ciurtin, Y. Majeed, C.J. Milligan, Y.M. Bahnasi, E. Al-Shawaf, K.E. Porter, L.H. Jiang, P. Emery, A. Sivaprasadarao, D.J. Beech, TRPC channel activation by extracellular thioredoxin, Nature 451 (2008) 69-72.

[152] C.O. Wong, P. Sukumar, D.J. Beech, X. Yao, Nitric oxide lacks direct effect on TRPC5 channels but suppresses endogenous TRPC5-containing channels in endothelial cells, Pflugers Arch. Eur. J. Physiol. 460 (2010) 121-130.

[153] J. Naylor, E. Al-Shawaf, L. McKeown, P.T. Manna, K.E. Porter, D. O'Regan, K. Muraki, D.J. Beech, TRPC5 channel sensitivities to antioxidants and hydroxylated stilbenes, J. Biol. Chem. 286 (2011) 5078-5083.

[154] J.W. Putney Jr., A model for receptor-regulated calcium entry, Cell Calcium 7 (1986) $1-12$.

[155] J.W. Putney Jr., Capacitative calcium entry revisited, Cell Calcium 11 (1990) 611-624.

[156] A. Zweifach, R.S. Lewis, Mitogen-regulated $\mathrm{Ca}^{2+}$ current of T lymphocytes is activated by depletion of intracellular $\mathrm{Ca}^{2+}$ stores, Proc. Natl. Acad. Sci. U. S. A. 90 (1993) 6295-6299.

[157] M. Hoth, R. Penner, Depletion of intracellular calcium stores activates a calcium current in mast cells, Nature 355 (1992) 353-356.

[158] M. Hoth, R. Penner, Calcium release-activated calcium current in rat mast cells, J. Physiol. 465 (1993) 359-386.

[159] S. Feske, Y. Gwack, M. Prakriya, S. Srikanth, S.H. Puppel, B. Tanasa, P.G. Hogan, R.S. Lewis, M. Daly, A. Rao, A mutation in Orai1 causes immune deficiency by abrogating CRAC channel function, Nature 441 (2006) 179-185.

[160] M. Vig, C. Peinelt, A. Beck, D.L. Koomoa, D. Rabah, M. Koblan-Huberson, S. Kraft, H. Turner, A. Fleig, R. Penner, J.P. Kinet, CRACM1 is a plasma membrane protein essential for store-operated $\mathrm{Ca}^{2+}$ entry, Science 312 (2006) 1220-1223.

[161] S.L. Zhang, A.V. Yeromin, X.H. Zhang, Y. Yu, O. Safrina, A. Penna, J. Roos, K.A. Stauderman, M.D. Cahalan, Genome-wide RNAi screen of $\mathrm{Ca}(2+)$ influx identifies genes that regulate $\mathrm{Ca}(2+)$ release-activated $\mathrm{Ca}(2+)$ channel activity, Proc. Natl. Acad. Sci. U. S. A. 103 (2006) 9357-9362.

[162] S.L. Zhang, Y. Yu, J. Roos, J.A. Kozak, T.J. Deerinck, M.H. Ellisman, K.A. Stauderman, M.D. Cahalan, STIM1 is a Ca2+ sensor that activates CRAC channels and migrates from the Ca2+ store to the plasma membrane, Nature 437 (2005) 902-905.

[163] J. Liou, M.L. Kim, D.H. Won, J.T. Jones, J.W. Myers, J.E. Ferrell Jr., T. Meyer, STIM is a Ca2+ sensor essential for Ca2+-store-depletion-triggered Ca2+ influx, Curr. Biol. 15 (2005) 1235-1241.

[164] J. Roos, P.J. DiGregorio, A.V. Yeromin, K. Ohlsen, M. Lioudyno, S. Zhang, O. Safrina, J.A. Kozak, S.L. Wagner, M.D. Cahalan, G. Veliçelebi, K.A. Stauderman, STIM1, an essential and conserved component of store-operated Ca2+ channel function, J. Cell Biol. 169 (2005) 435-445.

[165] K.T Cheng, X. Liu, H.L. Ong, I.S. Ambudkar, Functional requirement for Orai1 in store-operated TRPC1-STIM1 channels, J. Biol. Chem. 283 (2008) 12935-12940.

[166] J.P. Yuan, W. Zeng, G.N. Huang, P.F. Worley, S. Muallem, STIM1 heteromultimerizes TRPC channels to determine their function as store-operated channels, Nat. Cell Biol. 9 (2007) 636-645.

[167] C.Y. Park, A. Shcheglovitov, R. Dolmetsch, The CRAC channel activator STIM1 binds and inhibits L-type voltage-gated calcium channels, Science 330 (2010) 101-105. 
[168] Y. Wang, X. Deng, S. Mancarella, E. Hendron, S. Eguchi, J. Soboloff, X.D. Tang, D.L. Gill, The calcium store sensor, STIM1, reciprocally controls Orai and Ca V1. 2 channels, Science 330 (2010) 105-109.

[169] A. Zaidi, M.L. Michaelis, Effects of reactive oxygen species on brain synaptic plasma membrane Ca2+-ATPase, Free Radic. Biol. Med. 27 (1999) 810-821.

[170] P. Waring, Redox active calcium ion channels and cell death, Arch. Biochem. Biophys. 434 (2005) 33-42.

[171] A.B. Parekh, R. Penner, Activation of store-operated calcium influx at resting InsP3 levels by sensitization of the InsP3 receptor in rat basophilic leukaemia cells, J. Physiol. 489 (Pt 2) (1995) 377-382.

[172] L. Missiaen, C.W. Taylor, M.J. Berridge, Spontaneous calcium release from inositol trisphosphate-sensitive calcium stores, Nature 352 (1991) 241-244.

[173] M. Poitras, S. Bernier, M. Servant, D.E. Richard, G. Boulay, G. Guillemette, The high affinity state of inositol 1,4,5-trisphosphate receptor is a functional state, J. Biol. Chem. 268 (1993) 24078-24082.

[174] M. Hilly, F. Pietri-Rouxel, J.F. Coquil, M. Guy, J.P. Mauger, Thiol reagents increase the affinity of the inositol 1,4,5-trisphosphate receptor, J. Biol. Chem 268 (1993) 16488-16494.

[175] S.J. Elliott, S.G. Eskin, W.P. Schilling, Effect of t-butyl-hydroperoxide on bradykinin-stimulated changes in cytosolic calcium in vascular endothelial cells, J. Biol. Chem. 264 (1989) 3806-3810.

[176] K. Tornquist, P. Vainio, A. Titievsky, B. Dugue, R. Tuominen, Redox modulation of intracellular free calcium concentration in thyroid FRTL-5 cells: evidence for an enhanced extrusion of calcium, Biochem. J. 339 (Pt 3) (1999) 621628.

[177] K. Tornquist, P.J. Vainio, S. Bjorklund, A. Titievsky, B. Dugue, R.K. Tuominen Hydrogen peroxide attenuates store-operated calcium entry and enhances calcium extrusion in thyroid FRTL-5 cells, Biochem. J. 351 (2000) 47-56

[178] V. Imbert, J.F. Peyron, D. Farahi Far, B. Mari, P. Auberger, B. Rossi, Induction of tyrosine phosphorylation and T-cell activation by vanadate peroxide an inhibitor of protein tyrosine phosphatases, Biochem. J. 297 (Pt 1) (1994) 163-173.

[179] J.A. Rosado, P.C. Redondo, G.M. Salido, E. Gomez-Arteta, S.O. Sage, J.A. Pariente, Hydrogen peroxide generation induces pp60src activation in human platelets: evidence for the involvement of this pathway in store-mediated calcium entry, J. Biol. Chem. 279 (2004) 1665-1675.

[180] G.R. Ehring, H.H. Kerschbaum, C.M. Fanger, C. Eder, H. Rauer, M.D. Cahalan, Vanadate induces calcium signaling $\mathrm{Ca} 2+$ release-activated $\mathrm{Ca} 2+$ channel activation, and gene expression in T lymphocytes and RBL-2H3 mast cells via thiol oxidation, J. Immunol. 164 (2000) 679-687.

[181] S.M. Florea, L.A. Blatter, The effect of oxidative stress on Ca2+ release and capacitative Ca2+ entry in vascular endothelial cells, Cell Calcium 43 (2008) 405-415.

[182] C. Schach, M. Xu, O. Platoshyn, S.H. Keller, J.X. Yuan, Thiol oxidation causes pulmonary vasodilation by activating $\mathrm{K}+$ channels and inhibiting store-operated Ca2+ channels, Am. J. Physiol. Lung Cell Mol. Physiol. 292 (2007) L685L698.

[183] H.S. Zhang, J.H. Xiao, E.H. Cao, J.F. Qin, Homocysteine inhibits store-mediated calcium entry in human endothelial cells: evidence for involvement of membrane potential and actin cytoskeleton, Mol. Cell Biochem. 269 (2005) 37-47.

[184] G.R. Tintinger, A.J. Theron, M. Potjo, R. Anderson, Reactive oxidants regulate membrane repolarization and store-operated uptake of calcium by formyl peptide-activated human neutrophils, Free Radic. Biol. Med. 42 (2007) $1851-1857$

[185] P.C. Redondo, G.M. Salido, J.A. Pariente, J.A. Rosado, Dual effect of hydrogen peroxide on store-mediated calcium entry in human platelets, Biochem. Pharmacol. 67 (2004) 1065-1076.

[186] Y. Suzuki, T. Yoshimaru, T. Inoue, C. Ra, Discrete generations of intracellular hydrogen peroxide and superoxide in antigen-stimulated mast cells: reciprocal regulation of store-operated Ca2+ channel activity, Mol. Immunol. 46 (2009) 2200-2209.

[187] I. Bogeski, C. Kummerow, D. Al-Ansary, E.C. Schwarz, R. Koehler, D. Kozai, N. Takahashi, C. Peinelt, D. Griesemer, M. Bozem, Y. Mori, M. Hoth, B.A. Niemeyer, Differential redox regulation of ORAI ion channels: a mechanism to tune cellular calcium signaling, Sci. Signal. 3 (2010) ra24.

[188] B.J. Hawkins, K.M. Irrinki, K. Mallilankaraman, Y.C. Lien, Y. Wang C.D. Bhanumathy, R. Subbiah, M.F. Ritchie, J. Soboloff, Y. Baba, T. Kurosaki, S.K. Joseph, D.L. Gill, M. Madesh, S-glutathionylation activates STIM1 and alters mitochondrial homeostasis, J. Cell. Biol. 190 (2010) 391-405.

[189] M. Grupe, G. Myers, R. Penner, A. Fleig, Activation of store-operated I(CRAC) by hydrogen peroxide, Cell Calcium 48 (2010) $1-9$.

[190] N. Scrimgeour, T. Litjens, L. Ma, G.J. Barritt, G.Y. Rychkov, Properties of Orai1 mediated store-operated current depend on the expression levels of STIM1 and Orai1 proteins, J. Physiol. 587 (2009) 2903-2918.

[191] Z. Li, L. Liu, Y. Deng, W. Ji, W. Du, P. Xu, L. Chen, T. Xu, Graded activation of CRAC channel by binding of different numbers of STIM1 to Orai1 subunits, Cell. Res. 21 (2011) 305-315.

[192] I.F. Smith, J.P. Boyle, P.F. Vaughan, H.A. Pearson, C. Peers, Effects of chronic hypoxia on $\mathrm{Ca}(2+)$ stores and capacitative $\mathrm{Ca}(2+)$ entry in human neuroblastoma (SH-SY5Y) cells, J. Neurochem. 79 (2001) 877-884.

[193] M.L. Paffett, J.S. Naik, T.C. Resta, B.R. Walker, Reduced store-operated Ca2+ entry in pulmonary endothelial cells from chronically hypoxic rats, Am. J. Physiol. Lung Cell. Mol. Physiol. 293 (2007) L1135-L1142.

[194] M. Asai, K. Takeuchi, M. Saotome, T. Urushida, H. Katoh, H. Satoh, H. Hayashi, H. Watanabe, Extracellular acidosis suppresses endothelial function by inhibiting store-operated Ca2+ entry via non-selective cation channels, Cardiovasc. Res. 83 (2009) 97-105.

[195] J.B. Snow, N.L. Kanagy, B.R. Walker, T.C. Resta, Rat strain differences in pulmonary artery smooth muscle $\mathrm{Ca}(2+)$ entry following chronic hypoxia, Microcirculation 16 (2009) 603-614.

[196] I. Fantozzi, S. Zhang, O. Platoshyn, C.V. Remillard, R.T. Cowling, J.X. Yuan, Hypoxia increases AP-1 binding activity by enhancing capacitative Ca2+ entry in human pulmonary artery endothelial cells, Am. J. Physiol. Lung Cell. Mol. Physiol. 285 (2003) L1233-L1245.

[197] M.J. Lin, G.P. Leung, W.M. Zhang, X.R. Yang, K.P. Yip, C.M. Tse, J.S. Sham, Chronic hypoxia-induced upregulation of store-operated and receptor-operated $\mathrm{Ca} 2+$ channels in pulmonary arterial smooth muscle cells: a novel mechanism of hypoxic pulmonary hypertension, Circ. Res. 95 (2004) 496-505.

[198] J. Wang, L.A. Shimoda, L. Weigand, W. Wang, D. Sun, J.T. Sylvester, Acute hypoxia increases intracellular $[\mathrm{Ca} 2+]$ in pulmonary arterial smooth muscle by enhancing capacitative Ca2+ entry, Am. J. Physiol. Lung Cell. Mol. Physiol. 288 (2005) L1059-L1069.

[199] L.C. Ng, B.D. Kyle, A.R. Lennox, X.M. Shen, W.J. Hatton, J.R. Hume, Cell culture alters $\mathrm{Ca} 2+$ entry pathways activated by store-depletion or hypoxia in canine pulmonary arterial smooth muscle cells, Am. J. Physiol. Cell Physiol. 294 (2008) C313-C323.

[200] W. Lu, J. Wang, G. Peng, L.A. Shimoda, J.T. Sylvester, Knockdown of stromal interaction molecule 1 attenuates store-operated $\mathrm{Ca} 2+$ entry and $\mathrm{Ca} 2+$ responses to acute hypoxia in pulmonary arterial smooth muscle, Am. J. Physiol. Lung Cell. Mol. Physiol. 297 (2009) L17-L25.

[201] A. Berna-Erro, A. Braun, R. Kraft, C. Kleinschnitz, M.K. Schuhmann, D. Stegner, T. Wultsch, J. Eilers, S.G. Meuth, G. Stoll, B. Nieswandt, STIM2 regulates capacitive $\mathrm{Ca} 2+$ entry in neurons and plays a key role in hypoxic neuronal cell death, Sci. Signal. 2 (2009) ra67.

[202] P.T. Mungai, G.B. Waypa, A.Jairaman, M. Prakriya, D. Dokic, M.K. Ball, P.T. Schumacker, Hypoxia triggers AMPK activation through ROS-mediated activation of CRAC channels, Mol. Cell Biol. 17 (2011) 3531-3545.

[203] G. Bischof, J. Brenman, D.S. Bredt, T.E. Machen, Possible regulation of capacitative $\mathrm{Ca} 2+$ entry into colonic epithelial cells by NO and cGMP, Cell Calcium 17 (1995) 250-262.

[204] M.F. Hsu, Y.S. Chen, L.J. Huang, L.T. Tsao, S.C. Kuo, J.P. Wang, GEA3162, a nitric oxide-releasing agent, activates non-store-operated Ca2+ entry and inhibits store-operated $\mathrm{Ca} 2+$ entry pathways in neutrophils through thiol oxidation, Eur. J. Pharmacol. 535 (2006) 43-52.

[205] P.F. Blackmore, Biphasic effects of nitric oxide on calcium influx in human platelets, Thromb. Res. 127 (2011) e8-e14.

[206] R.A. Cohen, R.M. Weisbrod, M. Gericke, M. Yaghoubi, C. Bierl, V.M. Bolotina Mechanism of nitric oxide-induced vasodilatation: refilling of intracellular stores by sarcoplasmic reticulum Ca2+ ATPase and inhibition of storeoperated Ca2+ influx, Circ. Res. 84 (1999) 210-219.

[207] E.S. Trepakova, R.A. Cohen, V.M. Bolotina, Nitric oxide inhibits capacitative cation influx in human platelets by promoting sarcoplasmic/endoplasmic reticulum Ca2+-ATPase-dependent refilling of Ca2+stores, Circ. Res. 84(1999) 201-209.

[208] B. Thyagarajan, M. Poteser, C. Romanin, H. Kahr, M.X. Zhu, K. Groschner Expression of Trp3 determines sensitivity of capacitative Ca2+ entry to nitric oxide and mitochondrial Ca2+ handling: evidence for a role of Trp3 as a subunit of capacitative Ca2+ entry channels, J. Biol. Chem. 276 (2001) 48149-48158.

[209] B. Thyagarajan, R. Malli, K. Schmidt, W.F. Graier, K. Groschner, Nitric oxide inhibits capacitative Ca2+ entry by suppression of mitochondrial Ca2+ handling, Br. J. Pharmacol. 137 (2002) 821-830.

[210] Y. Okamoto, H. Ninomiya, S. Miwa, T. Masaki, Capacitative Ca2+ entry in human platelets is resistant to nitric oxide, Biochem. Biophys. Res. Commun. 212 (1995) 90-96.

[211] E.N. Dedkova, L.A. Blatter, Nitric oxide inhibits capacitative Ca2+ entry and enhances endoplasmic reticulum Ca2+ uptake in bovine vascular endothelial cells, J. Physiol. 539 (2002) 77-91.

[212] N.L. Jernigan, B.R. Broughton, B.R. Walker, T.C. Resta, Impaired NO-dependent inhibition of store- and receptor-operated calcium entry in pulmonary vascular smooth muscle after chronic hypoxia, Am. J. Physiol. Lung Cell. Mol. Physiol. 290 (2006) L517-L525.

[213] X. Xu, R.A. Star, G. Tortorici, S. Muallem, Depletion of intracellular Ca2+ stores activates nitric-oxide synthase to generate cGMP and regulate Ca2+ influx, J. Biol. Chem. 269 (1994) 12645-12653.

[214] C.J. Favre, C.A. Ufret-Vincenty, M.R. Stone, H.T. Ma, D.L. Gill, Ca2+ pool emptying stimulates Ca2+ entry activated by S-nitrosylation, J. Biol. Chem. 273 (1998) 30855-30858.

[215] H.T. Ma, C.J. Favre, R.L. Patterson, M.R. Stone, D.L. Gill, Ca(2+) entry activated by S-nitrosylation relationship to store-operated ca(2+) entry, J. Biol. Chem. 274 (1999) 35318-35324.

[216] E.L. Watson, K.L. Jacobson, J.C. Singh, S.M. Ott, Nitric oxide acts independently of cGMP to modulate capacitative $\mathrm{Ca}(2+)$ entry in mouse parotid acini, Am. J. Physiol. 277 (1999) C262-C270.

[217] Z. Moneer, J.L. Dyer, C.W. Taylor, Nitric oxide co-ordinates the activities of the capacitative and non-capacitative Ca2+-entry pathways regulated by vasopressin, Biochem. J. 370 (2003) 439-448.

[218] E.L. Watson, K.L. Jacobson, J.C. Singh, D.H. Dijulio, Arachidonic acid regulates two Ca2+ entry pathways via nitric oxide, Cell Signal. 16 (2004) 157-165. 
[219] D.L. Campbell, J.S. Stamler, H.C. Strauss, Redox modulation of L-type calcium channels in ferret ventricular myocytes. Dual mechanism regulation by nitric oxide and S-nitrosothiols, J. Gen. Physiol. 108 (1996) 277-293.

[220] H.M. Viola, P.G. Arthur, L.C. Hool, Transient exposure to hydrogen peroxide causes an increase in mitochondria-derived superoxide as a result of sustained alteration in L-type Ca2+ channel function in the absence of apoptosis in ventricular myocytes, Circ. Res. 100 (2007) 1036-1044.

[221] K. Yamaoka, M. Yakehiro, T. Yuki, H. Fujii, I. Seyama, Effect of sulfhydryl reagents on the regulatory system of the L-type Ca channel in frog ventricular myocytes, Pflugers Arch. 440 (2000) 207-215.

[222] K. Hudasek, S.T. Brown, I.M. Fearon, H2O2 regulates recombinant Ca2+ channel alpha1C subunits but does not mediate their sensitivity to acute hypoxia, Biochem. Biophys. Res. Commun. 318 (2004) 135-141.

[223] C. Peers, J.L. Scragg, J.P. Boyle, I.M. Fearon, S.C. Taylor, K.N. Green, N.J. Webster, M. Ramsden, H.A. Pearson, A central role for ROS in the functional remodelling of L-type Ca2+ channels by hypoxia, Philos. Trans. R. Soc. Lond. B Biol. Sci. 360 (2005) 2247-2254.

[224] J.L. Scragg, M.L. Dallas, J.A. Wilkinson, G. Varadi, C. Peers, Carbon monoxide inhibits L-type Ca2+ channels via redox modulation of key cysteine residues by mitochondrial reactive oxygen species, J. Biol. Chem. 283 (2008) 24412-24419.

[225] A. Lacampagne, A. Duittoz, P. Bolanos, N. Peineau, J.A. Argibay, Effect of sulfhydryl oxidation on ionic and gating currents associated with L-type calcium channels in isolated guinea-pig ventricular myocytes, Cardiovasc. Res. 30 (1995) 799-806.

[226] N. Chiamvimonvat, B. O’Rourke, T.J. Kamp, R.G. Kallen, F. Hofmann, V. Flockerzi, E. Marban, Functional consequences of sulfhydryl modification in the pore-forming subunits of cardiovascular $\mathrm{Ca} 2+$ and $\mathrm{Na}+$ channels, Circ. Res. 76 (1995) 325-334

[227] L. Guerra, E. Cerbai, S. Gessi, P.A. Borea, A. Mugelli, The effect of oxygen free radicals on calcium current and dihydropyridine binding sites in guinea-pig ventricular myocytes, Br. J. Pharmacol. 118 (1996) 1278-1284.

[228] P. Agostinho, C.B. Duarte, A.P. Carvalho, C.R. Oliveira, Oxidative stress affects the selective ion permeability of voltage-sensitive Ca2+ channels in cultured retinal cells, Neurosci. Res. 27 (1997) 323-334

[229] I.M. Fearon, A.C. Palmer, A.J. Balmforth, S.G. Ball, G. Varadi, C. Peers, Modulation of recombinant human cardiac L-type Ca2+ channel alpha1C subunits by redox agents and hypoxia, J. Physiol. 514 (Pt 3) (1999) 629-637.

[230] L.C. Hool, Hypoxia alters the sensitivity of the L-type $\mathrm{Ca}(2+)$ channel to alphaadrenergic receptor stimulation in the presence of beta-adrenergic receptor stimulation, Circ. Res. 88 (2001) 1036-1043.

[231] L.C. Hool, P.G. Arthur, Decreasing cellular hydrogen peroxide with catalase mimics the effects of hypoxia on the sensitivity of the L-type Ca2+ channel to beta-adrenergic receptor stimulation in cardiac myocytes, Circ. Res. 91 (2002) 601-609.

[232] L.C. Hool, C.A. Di Maria, H.M. Viola, P.G. Arthur, Role of NAD(P)H oxidase in the regulation of cardiac L-type Ca2+ channel function during acute hypoxia, Cardiovasc. Res. 67 (2005) 624-635.

[233] I.M. Fearon, A.D. Randall, E. Perez-Reyes, C. Peers, Modulation of recombinant T-type Ca2+ channels by hypoxia and glutathione, Pflugers Arch. 441 (2000) 181-188.

[234] S.M. Todorovic, V. Jevtovic-Todorovic, A. Meyenburg, S. Mennerick, E. PerezReyes, C. Romano, J.W. Olney, C.F. Zorumski, Redox modulation of T-type calcium channels in rat peripheral nociceptors, Neuron 31 (2001) 75-85.

[235] S.M. Todorovic, A. Meyenburg, V. Jevtovic-Todorovic, Redox modulation of peripheral T-type Ca2+ channels in vivo: alteration of nerve injury-induced thermal hyperalgesia, Pain 109 (2004) 328-339.

[236] M.T. Nelson, P.M. Joksovic, E. Perez-Reyes, S.M. Todorovic, The endogenous redox agent L-cysteine induces T-type Ca2+ channel-dependent sensitization of a novel subpopulation of rat peripheral nociceptors, J. Neurosci. 25 (2005) 8766-8775.

[237] P.M. Joksovic, M.T. Nelson, V. Jevtovic-Todorovic, M.K. Patel, E. Perez-Reyes, K.P. Campbell, C.C. Chen, S.M. Todorovic, CaV3.2 is the major molecular substrate for redox regulation of T-type $\mathrm{Ca} 2+$ channels in the rat and mouse thalamus, J. Physiol. 574 (2006) 415-430.

[238] A. Li, J. Segui, S.H. Heinemann, T. Hoshi, Oxidation regulates cloned neuronal voltage-dependent $\mathrm{Ca} 2+$ channels expressed in Xenopus oocytes, J. Neurosci. 18 (1998) 6740-6747.

[239] M. Kolisek, A. Beck, A. Fleig, R. Penner, Cyclic ADP-ribose and hydrogen peroxide synergize with ADP-ribose in the activation of TRPM2 channels, Mol. Cell. 18 (2005) 61-69.

[240] R. Kraft, C. Grimm, K. Grosse, A. Hoffmann, S. Sauerbruch, H. Kettenmann, G. Schultz, C. Harteneck, Hydrogen peroxide and ADP-ribose induce TRPM2mediated calcium influx and cation currents in microglia, Am. J. Physiol. Cell Physiol. 286 (2004) C129-C137.

[241] M. Ishii, A. Oyama, T. Hagiwara, A. Miyazaki, Y. Mori, Y. Kiuchi, S. Shimizu, Facilitation of H2O2-induced A172 human glioblastoma cell death by insertion of oxidative stress-sensitive TRPM2 channels, Anticancer Res. 27 (2007) 3987-3992.

[242] C.M. Hecquet, G.U. Ahmmed, S.M. Vogel, A.B. Malik, Role of TRPM2 channel in mediating $\mathrm{H} 2 \mathrm{O} 2$-induced $\mathrm{Ca} 2+$ entry and endothelial hyperpermeability, Circ. Res. 102 (2008) 347-355.

[243] J.A. Wilkinson, J.L. Scragg, J.P. Boyle, B. Nilius, C. Peers, H2O2-stimulated Ca2+ influx via TRPM2 is not the sole determinant of subsequent cell death, Pflugers Arch. 455 (2008) 1141-1151.

[244] G. Cao, K.P. Lee, J. van der Wijst, M. de Graaf, A. van der Kemp, R.J. Bindels, J.G. Hoenderop, Methionine sulfoxide reductase B1 (MsrB1) recovers TRPM6 channel activity during oxidative stress, J. Biol. Chem. 285 (2010) 26081-26087.

[245] B.F. Bessac, M. Sivula, C.A. von Hehn, J. Escalera, L. Cohn, S.E. Jordt, TRPA1 is a major oxidant sensor in murine airway sensory neurons, J. Clin. Invest. 118 (2008) 1899-1910.

[246] T.E. Taylor-Clark, M.A. McAlexander, C. Nassenstein, S.A. Sheardown, S. Wilson, J. Thornton, M.J. Carr, B.J. Undem, Relative contributions of TRPA1 and TRPV1 channels in the activation of vagal bronchopulmonary C-fibres by the endogenous autacoid 4-oxononenal, J. Physiol. 586 (2008) 3447-3459.

[247] Y.S. Lin, C.C. Hsu, M.Y. Bien, H.C. Hsu, H.T. Weng, Y.R. Kou, Activations of TRPA1 and P2X receptors are important in ROS-mediated stimulation of capsaicinsensitive lung vagal afferents by cigarette smoke in rats, J. Appl. Physiol. 108 (2010) 1293-1303

[248] H.H. Chuang, S. Lin, Oxidative challenges sensitize the capsaicin receptor by covalent cysteine modification, Proc. Natl. Acad. Sci. U. S. A. 106 (2009) 20097-20102.

[249] E. Kishimoto, Y. Naito, O. Handa, H. Okada, K. Mizushima, Y. Hirai, N. Nakabe, K. Uchiyama, T. Ishikawa, T. Takagi, N. Yagi, S. Kokura, N. Yoshida, T. Yoshikawa, Oxidative stress-induced post-translational modification of TRPV1 expressed in esophageal epithelial cells, Am. J. Physiol. Gastrointest. Liver Physiol. 301 (2011) G230-G238.

[250] Y. Jin, D.K. Kim, L.Y. Khil, U. Oh, J. Kim, J. Kwak, Thimerosal decreases TRPV1 activity by oxidation of extracellular sulfhydryl residues, Neurosci. Lett. 369 (2004) 250-255

[251] Z. Wang, X. Wei, Y. Zhang, X. Ma, B. Li, S. Zhang, P. Du, X. Zhang, F. Yi, NADPH oxidase-derived ROS contributes to upregulation of TRPC6 expression in puromycin aminonucleoside-induced podocyte injury, Cell. Physiol. Biochem. 24 (2009) 619-626.

[252] S. Graham, M. Ding, Y. Ding, S. Sours-Brothers, R. Luchowski, Z. Gryczynski, T. Yorio, H. Ma, R. Ma, Canonical transient receptor potential 6 (TRPC6), a redox-regulated cation channel, J. Biol. Chem. 285 (2010) 23466-23476. 